\title{
COMPOSTOS CARBONÍLICOS ATMOSFÉRICOS: FONTES, REATIVIDADE, NÍVEIS DE CONCENTRAÇÃO E EFEITOS TOXICOLÓGICOS
}

Marta Valéria Almeida Santana de Andrade

Departamento de Ciências Exatas e da Terra, Universidade do Estado da Bahia, Estrada das Barreiras, s/n, 41195-001 Salvador - BA Heloisa Lúcia Castellar Pinheiro

Departamento de Ciências da Terra, Centro Federal de Ensino Técnico da Bahia, Rua Emídio Santos, s/n, 40625-650 Salvador - BA Pedro Afonso de Paula Pereira e Jailson Bittencourt de Andrade*

Instituto de Química, Universidade Federal da Bahia, Campus de Ondina, 40170-290 Salvador - BA

Recebido em 16/8/01; aceito em 10/4/02

\begin{abstract}
ATMOSPHERIC CARBONYL COMPOUNDS: SOURCES, REACTIVITY, CONCENTRATION LEVELS AND TOXICOLOGIC EFFECTS. In the last three decades carbonyl compounds, aldehydes and ketones, have received a great deal of attention due to their strong influence on photochemical smog formation and their recognized adverse human health effects. Carbonyl compounds are directly emitted into the atmosphere by combustion sources and also produced from photochemical oxidation of hydrocarbons and other organic compounds. In this paper it is presented a general overview about the carbonyl compounds sources, reactivity, concentration levels and toxicological effects.
\end{abstract}

Keywords: aldehydes; carbonyl compounds; ketones.

\section{INTRODUÇÃO}

Os compostos carbonílicos (CC), aldeídos e cetonas, são emitidos diretamente para atmosfera por um grande número de fontes e desempenham um papel de grande relevância na química atmosférica por resultarem da primeira fotooxidação dos hidrocarbonetos, por configurar-se a maior fonte de radicais livres e como precursores de aerossol orgânico em áreas urbanas ${ }^{1-4}$.

Dentre os compostos carbonílicos atmosféricos, os mais abundantes são o formaldeído $(\mathrm{HCHO})$ e o acetaldeído $\left(\mathrm{CH}_{3} \mathrm{CHO}\right)^{2}$, embora exista uma fração significativa desses compostos (cerca de 10\%) sob forma de propionaldeído $\left(\mathrm{CH}_{3} \mathrm{CH}_{2} \mathrm{CHO}\right)$, propanona $\left(\mathrm{CH}_{3} \mathrm{COCH}_{3}\right)$, acroleína $\left(\mathrm{CH}_{2}=\mathrm{CHCHO}\right)$ e benzaldeído $\left(\mathrm{C}_{6} \mathrm{H}_{5} \mathrm{CHO}\right)$, entre outros 5 .

Os aldeídos e cetonas afetam a química atmosférica de áreas poluídas por uma série de rotas bastante complexas. $\mathrm{O}$ aumento da concentração desses compostos diminui o período de indução de geração do "smog" fotoquímico, devido a alta reatividade dos mesmos, além de aumentar a concentração de ozônio na troposfera, o que é indesejável. Com exceção do formaldeído, os outros compostos carbonílicos são os principais precursores de uma importante classe de poluentes secundários, os nitratos de peroxiacila (PANs) e os nitratos de peroxibenzila (PBNs), os quais são altamente irritantes para os olhos e fitotóxicos. Os compostos carbonílicos também são importantes precursores dos ácidos orgânicos atmosféricos, contribuindo assim para a chuva ácida e acidificação de lagos. Dessa forma, os compostos carbonílicos afetam a qualidade do ar ambiente de forma direta e também indiretamente, através de suas transformações químicas, geração do "smog" fotoquímico e interação com outros poluentes ${ }^{1}$.

\section{FONTES}

Os compostos carbonílicos podem ser emitidos para a atmosfera a partir de uma grande variedade de fontes naturais e antropogênicas e, podem ser formados in situ a partir da fotólise e fotoxidação de

*e-mail: jailsong@ufba.br hidrocarbonetos e outros compostos orgânicos atmosféricos ${ }^{1,3,6}$.

\section{Fontes naturais}

As fontes naturais contribuem com uma pequena quantidade de compostos carbonílicos para a atmosfera. Porém esta fração é significativa em áreas remotas que não sofrem influência de emissões antropogênicas.

A queima espontânea de florestas é o principal mecanismo de emissão natural de CC para atmosfera. Estas emissões são importantes, mas difíceis de serem caracterizadas devido à grande variedade das plantas (material queimado), e das condições em que são queimadas. Nestas emissões são encontrados aldeídos alifáticos, olefínicos, aromáticos e cíclicos, como mostra a Tabela 1. É importante ressaltar que as plantas também emitem CC através de diferentes mecanismos (respiração, degradação, entre outros), porém existem poucos estudos nessa área ${ }^{1}$.

Os animais constituem outra importante fonte de compostos carbonílicos para o ar, os quais são emitidos através dos excrementos ${ }^{1}$. Alguns insetos também contribuem com pequenas quantidades ${ }^{1,3,7}$. Como exemplo, podemos citar a identificação de compostos voláteis em feromônios ${ }^{7}$, na análise de glândulas de formigas Myrmica Rubra $L$, que indicou a presença de alguns aldeídos, tais como acetaldeído, propionaldeído, metilpropanal, 2 ou 3-metilbutanal, e cetonas como propanona, butanona e butenona.

Também foram detectadas emissões de alguns CC em gases vulcânicos ${ }^{1,3,8}$, como por exemplo, no vulcão Santiaguito, na Guatemala, onde foram encontrados acetaldeído, propionaldeído, propanona, metil-acroleína e metil-etil-cetona ${ }^{8}$.

\section{Fontes antropogênicas}

As emissões de compostos carbonílicos primários para o ambiente resultam das várias atividades antropogênicas, das quais podem-se destacar as indústrias, o uso de combustíveis, a incineração de lixo, a queima de madeira e a queima de florestas ${ }^{1,3,8}$. 
Tabela 1. Compostos carbonílicos emitidos pela vegetação e pela queima de florestas ${ }^{\mathrm{a}}$

\begin{tabular}{lll}
\hline Classificação & Vegetação & Queima de florestas \\
\hline Alifáticos & $\begin{array}{l}\text { formaldeído, acetaldeído, propanal, n-butanal, isobutanal, } \\
\text { n-pentanal, heptanal, octanal, nonanal, decanal, undecanal, } \\
\text { tetradecanal }\end{array}$ & $\begin{array}{l}\text { formaldeído, acetaldeído, } \\
\text { propanal, n-butanal, } \\
\text { isobutanal. }\end{array}$ \\
hexenal 2, trans-2-hexenal; 3,7-dimetil-2,6-octadienal, 3,7-dimetil- & acroleína \\
6-octenal, 4-hidroxi-3,7-dimetil-6-octenal, 2,6-nonadienal & $\begin{array}{l}\text { benzaldeído, cuminaldeído, dihidroxicuminaldeído, fenilpropanal, } \\
\text { cinamaldeído, p-hidroxibenzaldeído, anisaldeído, }\end{array}$ & $\begin{array}{l}\text { vanilina, coniferaldeído, } \\
\text { siringaldeído, sinapaldeído } \\
\text { o-metoxicinamaldeído, piperonal, vanilina, veratraldeído, } \\
\text { coniferaldeído, everniceraldeído } \\
\text { Cíclicos }\end{array}$ \\
\hline
\end{tabular}

${ }^{a}$ Adaptada da ref. 1

As indústrias que mais emitem CC são aquelas que sintetizam e/ ou usam esses compostos como matéria prima: refinarias e petroquímica; plantas de tratamento de esgotos; indústrias de plásticos, tintas e vernizes, entre outras. As emissões podem ocorrer nas várias etapas do processo industrial: através de escapamentos na linha, queima de combustíveis, esgotos industriais, armazenamento e transporte ${ }^{1}$.

A queima de combustíveis leva ao acúmulo direto e indireto de $\mathrm{CC}$ no ar, pois estes compostos estão presentes, mesmo que em níveis de traços, em qualquer processo de combustão. Em áreas urbanas, a queima de combustíveis por veículos tem se tornado a principal fonte de CC para a atmosfera, conseqüentemente sua emissão afeta diretamente o perfil dos níveis de concentração desses compostos no ar. Por sua vez, essas emissões dependem principalmente do combustível utilizado, do uso de catalisadores, e das condições do veículo e de tráfego ${ }^{9,10}$.

Nas últimas décadas, o estudo das emissões veiculares de CC tem recebido mais atenção dos pesquisadores devido ao aumento na utilização de combustíveis alternativos derivados de biomassa ${ }^{11-17}$, como por exemplo metanol e etanol ${ }^{18,19}$. O uso desses combustíveis tem como principal objetivo a melhoria da qualidade do ar em áreas urbanas através da redução da emissão de monóxido de carbono (CO) e hidrocarbonetos, levando a concentração atmosférica destes poluentes para valores abaixo dos exigidos nos padrões de qualidade do ar. Porém, as emissões desses combustíveis não queimados e de compostos carbonílicos, não são levadas em consideração pois para esses compostos não existem padrões de emissão.

O estudo do impacto provocado pelo uso de combustíveis oxigenados em veículos automotivos, no perfil das concentrações de $\mathrm{CC}$ no ar é de grande importância. Entretanto, no Brasil esse estudo é dificultado pela inexistência de dados anteriores à introdução de etanol hidratado como combustível veicular, em 1979.

Resultados comparativos entre as emissões de veículos movidos a combustíveis oxigenados (metanol e etanol) e gasolina mostram que os veículos leves que utilizam álcool como combustível emitem mais aldeídos que os veículos a gasolina ${ }^{9,10,14-17}$. Os veículos movidos a metanol e etanol aumentam respectivamente, os níveis de emissões de formaldeído e acetaldeído, através da combustão incompleta desses combustíveis. Vale ressaltar que esses aldeídos são mais reativos na atmosfera que seus respectivos álcoois ${ }^{20}$.

Estudos anteriores ${ }^{16}$ indicaram que as concentrações atmosféricas de formaldeído e acetaldeído apresentam uma relação estreita com a composição da frota veicular, para a cidade de Salvador Bahia, localizada na costa do Atlântico no Brasil, a 1301' S e 38 31'O. Desse modo, conhecendo a assinatura (razão $[\mathrm{HCHO}] /\left[\mathrm{CH}_{3} \mathrm{CHO}\right]$ ) da frota veicular a diesel e de veículos leves (gasolina e álcool) podese estimar, com excelente aproximação, a razão [HCHO]/[C $\left.\mathrm{CH}_{3} \mathrm{CHO}\right]$ a partir da contagem do tráfego local usando a equação:

$$
[\mathrm{HCHO}] /\left[\mathrm{CH}_{3} \mathrm{CHO}\right]=\frac{\mathrm{NVD} \times 4,4+\mathrm{NVL} \times 0,65}{(\mathrm{NVD}+\mathrm{NVL})}
$$

onde: $4,4=$ assinatura dos veículos a diesel ${ }^{16}$;

$0,65=$ assinatura da frota de veículos leves $\left(\right.$ para Salvador) ${ }^{16}$;

NVD = número de veículos a diesel;

NVL = número de veículos leves (gasolina e álcool).

Os resultados para as razões $[\mathrm{HCHO}] /\left[\mathrm{CH}_{3} \mathrm{CHO}\right]$ medidas e calculadas com a equação 1, para três sítios de amostragem em Salvador-Bahia, apresentaram uma boa correlação, conforme dados mostrados na Tabela $2^{16}$.

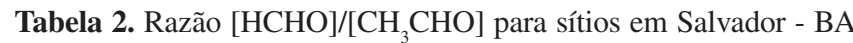

\begin{tabular}{lcc}
\hline Sítio de amostragem & $\begin{array}{c}{[\mathrm{HCHO}] /\left[\mathrm{CH}_{3} \mathrm{CHO}\right]} \\
\text { medida }^{a}\end{array}$ & $\begin{array}{c}{[\mathrm{HCHO}] /\left[\mathrm{CH}_{3} \mathrm{CHO}\right]} \\
\text { calculada }\end{array}$ \\
\hline Túnel Américo Simas & $1,2 \pm 0,24(4)$ & 1,3 \\
Baixa dos Sapateiros & $1,8 \pm 0,48(24)$ & 1,7 \\
Rio Vermelho & $1,0 \pm 0,51(17)$ & 0,62
\end{tabular}

a ) número de medidas

\section{Formação in situ}

Os processos de formação de CC na atmosfera contribuem com 45 - $95 \%$ dos aldeídos totais ${ }^{2}$. O mais importante desses processos é a fotooxidação de hidrocarbonetos alifáticos e aromáticos de origem natural e antropogênica, além de que todos os compostos orgânicos presentes na atmosfera podem gerar CC por esse mecanismo.

A produção de $\mathrm{CC}$ depende da formação de radicais livres $\mathrm{R}$; a partir de compostos orgânicos na atmosfera. Por sua vez, os radicais livres $\mathrm{R}^{\bullet}$ são formados pelo ataque de espécies reativas, como $\mathrm{HO}^{*}$, $\mathrm{HO}_{2}, \mathrm{O}_{3}$ e $\mathrm{NO}_{\mathrm{x}}$ aos compostos orgânicos.

\section{Áreas não poluídas}

Em áreas não poluídas ${ }^{1,3,21,22}$ os principais precursores dos CC são os hidrocarbonetos de origem natural, que são provenientes de gases que escapam da terra, emissões de plantas e animais, gases vulcânicos, entre outros. Nessas áreas, o hidrocarboneto mais abundante é o metano $\left(\mathrm{CH}_{4}\right)$, cuja concentração é cerca de 2 ppm, en- 
quanto os outros hidrocarbonetos ocorrem em concentrações significativamente menores. Como conseqüência, o formaldeído é o CC mais abundante, cuja principal fonte é o ataque de radicais $\mathrm{HO}^{*}$ ao metano, conforme mostra a seqüência de reações nas equações $2-7$, que estão esquematizadas na Figura 1.

$\mathrm{CH}_{4}+\mathrm{HO}^{\cdot} \rightarrow \mathrm{H}_{2} \mathrm{O}+\mathrm{CH}_{3} \cdot$

$\mathrm{CH}_{3}^{\cdot}+\mathrm{O}_{2}+\mathrm{M} \rightarrow \mathrm{CH}_{3} \mathrm{O}_{2}^{\cdot}+\mathrm{M}$

$\mathrm{CH}_{3} \mathrm{O}_{2}+\mathrm{NO} \rightarrow \mathrm{CH}_{3} \mathrm{O}^{*}+\mathrm{NO}_{2}$

$\mathrm{CH}_{3} \mathrm{O}^{*}+\mathrm{O}_{2} \rightarrow \mathbf{H C H O}+\mathrm{HO}_{2}^{*}$

ou

$\mathrm{CH}_{3} \mathrm{O}_{2}^{\cdot}+\mathrm{CH}_{3} \mathrm{O}_{2}^{\cdot} \rightarrow \mathrm{CH}_{3} \mathrm{O}^{\bullet}+\mathrm{CH}_{3} \mathrm{O}^{\bullet}+\mathrm{O}_{2}$
$\mathrm{CH}_{3} \mathrm{O}^{*}+\mathrm{O}_{2} \rightarrow \mathbf{H C H O}+\mathrm{HO}_{2}^{-}$
$\mathrm{CH}_{3} \mathrm{O}_{2}^{\cdot}+\mathrm{CH}_{3} \mathrm{O}_{2}^{\cdot} \rightarrow \mathbf{H C H O}+\mathrm{CH}_{3} \mathrm{OH}+\mathrm{O}_{2}$

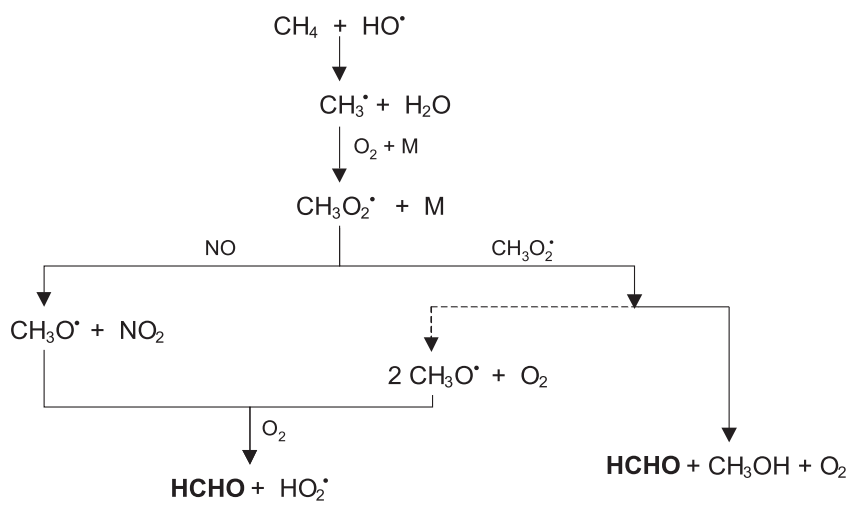

Figura 1. Formação de formaldeído $(\mathrm{HCHO})$ a partir do metano $\left(\mathrm{CH}_{4}\right)$. A reação representada com linha pontilhada é a menos importante

A constante de velocidade para a reação 6 é menor que para as reações 4 e 7, que são dominantes; as reações 4 e 7 competem entre si dependendo da concentração de $\mathrm{NO}_{x}$ na troposfera ${ }^{1,3}$. Sobre os continentes, onde a concentração de NO varia de 20 pptv a níveis acima de 1 ppbv, a reação 4 é dominante, enquanto que, sobre os oceanos, onde esse nível cai para menos que 10 pptv, a reação 7 predomina, podendo ocorrer também as reações 5 e 6 .

\section{Áreas poluídas}

Em áreas poluídas, os principais precursores dos compostos carbonílicos são os hidrocarbonetos de origem antropogênica e natural, através do ataque de radicais $\mathrm{HO}^{*}$ e ozônio presentes na atmosfera $^{1,3,17,22}$. Porém, muitos outros compostos orgânicos atmosféricos, como álcoois, éteres e compostos aromáticos, entre outros, podem dar origem aos CC.

O mecanismo básico de produção de $\mathrm{CC}$ a partir de radicais $\mathrm{R}^{\cdot}$ formados pelo ataque de espécies reativas $\left(\mathrm{O}_{3}, \mathrm{HO}^{\circ}, \mathrm{HO}_{2}^{\circ}, \mathrm{NO}_{3}^{\circ}\right)$ a compostos orgânicos no ar pode ser representado genericamente pelas equações $8-10$ :

$\mathrm{R}^{\cdot}+\mathrm{O}_{2} \rightarrow \mathrm{RO}_{2}$

$\mathrm{RO}_{2}^{\cdot}+\mathrm{NO} \rightarrow \mathrm{RO}^{*}+\mathrm{NO}_{2}$

$\mathrm{RO}^{\circ}+\mathrm{O}_{2} \rightarrow \mathbf{C C}+\mathrm{HO}_{2}^{\cdot}$

Durante o dia as reações 8 - 10 são muito rápidas, conseqüientemente a produção de CC é controlada pela formação de radicais livres $R^{*}$ que, por sua vez, depende da concentração de espécies reativas e das constantes de velocidade das reações entre essas espécies e os compostos orgânicos na troposfera ${ }^{1,3}$.
De modo contrário, durante a noite a concentração de NO é sempre mais baixa que durante o dia, pois sua principal fonte é a fotooxidação de $\mathrm{NO}_{2}$, por radiações de comprimento de onda entre 280 a $480 \mathrm{~nm}$ (equação 11):

$\mathrm{NO}_{2}+\mathrm{hv} \rightarrow \mathrm{NO}+\mathrm{O}^{*}(3 \mathrm{P})$

conseqüentemente, a reação 9 não é favorecida e o radical $\mathrm{RO}_{2}$ 'reage preferencialmente pelas seguintes rotas:

$\mathrm{RO}_{2}^{\cdot}+\mathrm{NO}_{2}+\mathrm{M} \rightarrow \mathrm{ROONO}_{2}+\mathrm{M}$

$\mathrm{RO}_{2}^{\circ}+\mathrm{O}_{3} \rightarrow \mathrm{RO}^{*}+2 \mathrm{O}_{2}$

$\begin{aligned} \mathrm{R}_{(1)} \mathrm{O}_{2}^{\cdot}+\mathrm{R}_{(2)} \mathrm{O}_{2}^{\cdot} & \rightarrow \mathrm{R}_{(1)} \mathrm{O}^{*}+\mathrm{R}_{(2)} \mathrm{O}^{*}+\mathrm{O}_{2} \\ & \rightarrow \mathrm{R}_{(1)}-\mathrm{O}-\mathrm{O}-\mathrm{R}_{(2)}+\mathrm{O}_{2} \\ & \rightarrow \text { álcool + aldeído }+\mathrm{O}_{2}\end{aligned}$

onde, $\mathrm{R}_{(1)}$ e $\mathrm{R}_{(2)}$ representam átomos de hidrogênio ou grupos orgânicos. O produto da reação 14 depende da natureza dos radicais $\mathrm{R}_{(1)} \mathrm{e}$ $\mathrm{R}_{(2)}$ : a) para $\mathrm{R}_{(1)}=\mathrm{R}_{(2)}=\mathrm{H}$ somente a reação $14 \mathrm{~b}$ pode ocorrer; $\mathrm{b}$ ) quando apenas $\mathrm{R}_{(1)}=\mathrm{H}$ ou $\mathrm{R}_{(2)}=\mathrm{H}$ só existe evidência direta da reação 14 b. A reação 14 c, que produz álcool $\left(\right.$ ou $\left.\mathrm{H}_{2} \mathrm{O}\right)$, aldeído e $\mathrm{O}_{2}$ é termodinamicamente favorável e deve ocorrer, contanto que o grupo orgânico possua um $\alpha \mathrm{H}$, enquanto a reação $14 \mathrm{a}$ que produz radicais $\mathrm{HO}^{*}$ é extremamente endotérmica, e portanto desfavorável ${ }^{1,3}$.

Nesse caso, os peróxidos orgânicos resultantes são instáveis e sofrem decomposição térmica formando radicais alcoxi que podem produzir CC. No entanto, os mecanismos noturnos são menos favoráveis que os mecanismos diurnos, sob forte irradiação solar. Isso explica o fato da produção de CC secundários ser muito maior durante o dia que a noite.

Os principais precursores dos compostos carbonílicos, entre os compostos orgânicos atmosféricos, são os alcanos e alcenos. Os alcinos são raros e menos reativos que os alcanos e alcenos; e, como conseqüência, sem importância para as reações químicas na troposfera.

\section{Ataque de radicais $\mathrm{HO}^{\circ}$ a alcanos}

As evidências sugerem que o principal mecanismo de remoção dos alcanos da troposfera envolve o ataque por radicais $\mathrm{HO}^{\circ}$, os quais reagem com esses compostos por eliminação de um átomo de hidrogênio ${ }^{1,3}$, como mostra a equação 15 para o propano:

$\mathrm{CH}_{3} \mathrm{CH}_{2} \mathrm{CH}_{3}+\mathrm{HO} \longrightarrow \mathrm{CH}_{3} \mathrm{CH}_{2} \mathrm{CH}_{2}^{+}+\mathrm{H}_{2} \mathrm{O}$

As constantes de velocidade para as reações entre alcanos e radicais HO` aumentam com o aumento da cadeia carbônica, como mostra a Tabela 3 para alguns compostos.

Tabela 3. Constantes de velocidade para reações entre alcanos e radicais $\mathrm{OH}^{\cdot}$ a $25^{\circ} \mathrm{C}(298 \mathrm{~K}), 1984^{\mathrm{a}}$

\begin{tabular}{lcc}
\hline Alcano & $\begin{array}{c}\text { Constante de velocidade } \\
\left(\mathrm{cm}^{3} \text { molécula }^{-1} \mathrm{~s}^{-1}\right)\end{array}$ & Referência \\
\hline Metano & $8,0 \times 10^{-15}$ & 23 \\
Etano & $2,7 \times 10^{-13}$ & 23 \\
Propano & $1,2 \times 10^{-12}$ & 23 \\
n-Butano & $2,58 \times 10^{-12}$ & 24 \\
2,3-Dimetil butano & $6,3 \times 10^{-12}$ & 24 \\
\hline
\end{tabular}

${ }^{\text {a }}$ Adaptada da ref. 3. 


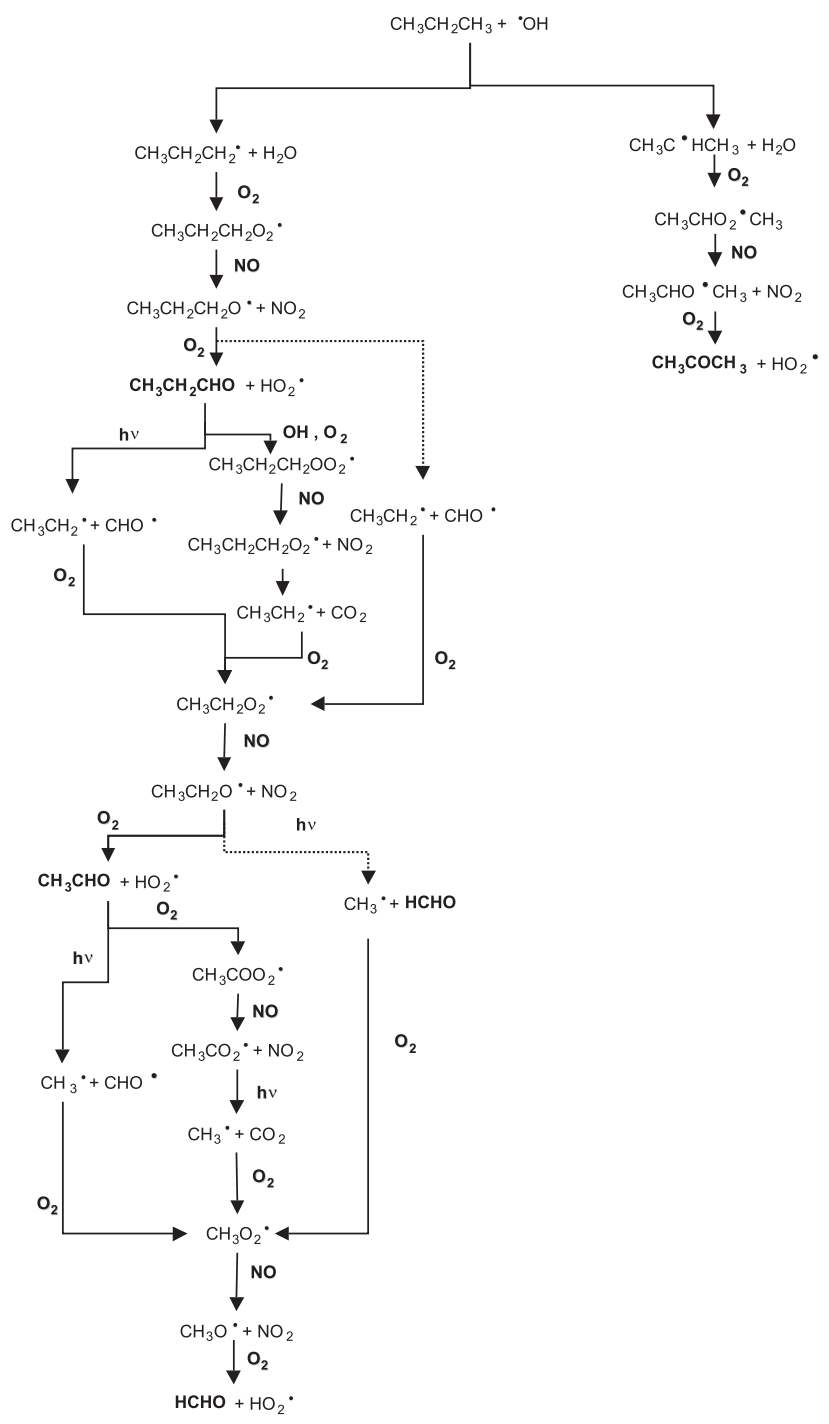

Figura 2. Formação de CC a partir do ataque de radicais $\mathrm{HO}$ à molécula do propano. As reações representadas com linha pontilhada são menos importantes

A Figura 2 mostra a formação de CC a partir do ataque de radicais HO` à molécula de propano. É importante observar no curso das reações apresentadas, na referida figura, que partindo do propano pode-se obter todos os possíveis CC com 3 ou menos átomos de carbono.

\section{Ataque de radicais $\mathrm{HO}^{*}$ a alcenos}

Os alcenos são considerados os principais precursores de compostos carbonílicos em atmosferas poluídas ${ }^{1,3}$, porque os CC são os principais produtos da interação entre os alcenos e radicais $\mathrm{HO}^{*}$. Além disso, os alcenos são mais reativos que os alcanos, como pode-se observar quando se compara a reatividade dos alcanos (Tabela 3) e alcenos (Tabela 4) com radicais $\mathrm{HO}^{*}$.

Os alcenos podem reagir com radicais $\mathrm{HO}^{\bullet}$ por dois caminhos:

a) Por transferência de hidrogênio, neste caso os $\alpha \mathrm{H}$ da dupla ligação são mais reativos, visto que o radical obtido é estabilizado por ressonância alílica, como por exemplo no buteno 1 :

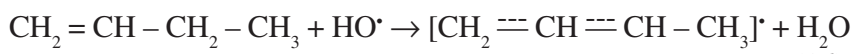

Tabela 4. Constantes de velocidade para reações entre alcenos e radicais $\mathrm{OH}^{\cdot}$ a $25^{\circ} \mathrm{C}(298 \mathrm{~K}), 1984^{\mathrm{a}}$

\begin{tabular}{lcc}
\hline Alceno & $\begin{array}{c}\text { Constante de velocidade } \\
\left(\mathrm{cm}^{3} \text { molécula }^{-1} \mathrm{~s}^{-1}\right)\end{array}$ & Referência \\
\hline Eteno & $9,0 \times 10^{-12}$ & 23 \\
Propeno & $3,0 \times 10^{-11}$ & 23 \\
1-Buteno & $3,3 \times 10^{-11}$ & 24 \\
Trans-2-buteno & $7,0 \times 10^{-11}$ & 24 \\
\hline
\end{tabular}

adaptada da ref. 3.

b) Por adição do radical HO• à dupla ligação, que é provavelmente o mecanismo dominante. Para o buteno 1, por exemplo, onde devem ocorrer a adição terminal e interna podemos obter:

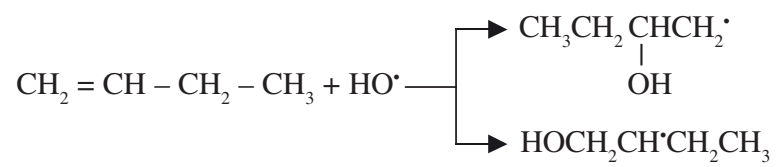

Os radicais formados reagem com oxigênio, depois com NO para em seguida gerar CC, segundo o mecanismo geral (reações 8 - 10), conforme é mostrado na Figura 3 para o propeno.

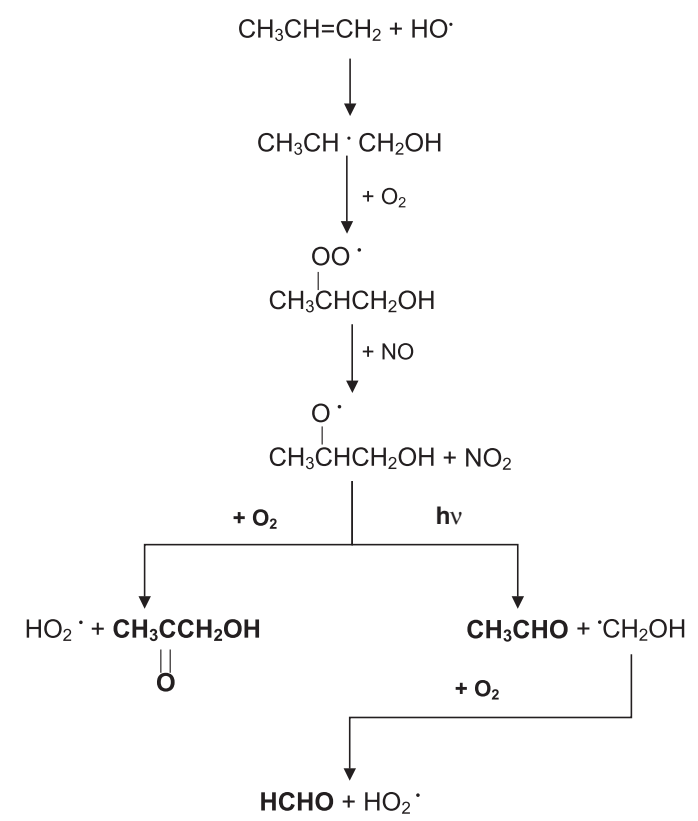

Figura 3. Formação de CC a partir do ataque de radicais $\mathrm{HO}^{*}$ à molécula do propeno

\section{Reação de alcenos com ozônio}

Outra importante rota de formação de compostos carbonílicos na atmosfera, que tem sido bastante estudada, é a reação de alcenos com ozônio ${ }^{25-35}$ (reações 18 e 19). A primeira etapa dessa reação envolve a formação de um ozonídeo:

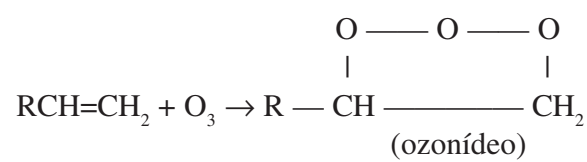


Esta espécie é extremamente instável e energética, sofrendo dissociação espontânea para formar um composto carbonílico e um birradical:

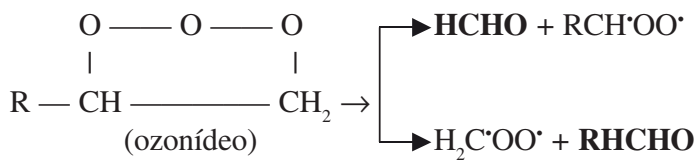

Os birradicais assim formados podem reagir por diversas rotas para gerar novos CC. Entre essas rotas podemos citar a reação com espécies facilmente oxidadas, como por exemplo $\mathrm{NO}, \mathrm{NO}_{2}$ e $\mathrm{SO}_{2}$ :

$$
\begin{aligned}
\mathrm{RCH}^{\circ} \mathrm{OO}^{*} & +\mathrm{NO} \rightarrow \mathbf{R C H O}+\mathrm{NO}_{2} \\
& +\mathrm{NO}_{2} \rightarrow \mathbf{R C H O}+\mathrm{NO}_{3} \cdot \\
& +\mathrm{SO}_{2} \rightarrow \mathbf{R C H O}+\mathrm{SO}_{3} \\
\mathrm{CH}_{2} \mathrm{OO}^{\circ} & +\mathrm{NO} \rightarrow \mathbf{H C H O}+\mathrm{NO}_{2} \\
& +\mathrm{NO}_{2} \rightarrow \mathbf{H C H O}+\mathrm{NO}_{3} \cdot \\
& +\mathrm{SO}_{2} \rightarrow \mathbf{H C H O}+\mathrm{SO}_{3}
\end{aligned}
$$

Devido à menor reatividade do ozônio em relação a outros oxidantes fotoquímicos, esse mecanismo de formação de CC só se torna relevante em condições de severa poluição fotoquímica. Portanto, em áreas poluídas, é uma importante fonte de CC à noite.

\section{PROCESSOS DE REMOÇÃO DA ATMOSFERA}

Os compostos carbonílicos podem ser removidos da atmosfera através de uma série de processos, sendo os principais a fotólise e a reação com radicais $\mathrm{HO}^{\cdot 1,3,22,36}$. Além destes, pode-se destacar as reações com $\mathrm{HO}_{2}{ }^{\circ}, \mathrm{O}_{3}, \mathrm{NO}_{3}{ }^{\circ}$ e $\mathrm{O}^{\circ}(3 \mathrm{P})$ e os processos de deposição seca e úmida.

Os processos de remoção de CC da atmosfera são de grande importância, pois influem de forma significativa na formação do "smog" fotoquímico por uma série de rotas: a) formação de poluentes secundários, dos quais destacam-se os nitratos de peroxialquila e os nitratos de peroxiarila; b) aumento dos níveis de concentração de ozônio na troposfera e c) principais precursores de radicais livres. Além desses aspectos, os CC desempenham um papel relevante na química dos aerossóis e na deposição úmida. Como exemplo, acredita-se que a fotólise destes compostos em gotas de chuva seja a maior fonte de peróxido de hidrogênio, um importante oxidante de $\mathrm{SO}_{2}$ dissolvido ${ }^{1,12,37}$.

\section{Fotólise}

A fotólise de CC na atmosfera é uma importante fonte de monóxido de carbono $(\mathrm{CO})$, radical $\mathrm{HO}_{2}{ }^{-}$- importante precursor de $\mathrm{H}_{2} \mathrm{O}_{2}$ - e radicais peroxi-alquila ou peroxi-arila ${ }^{1,3,12,17}$.

Fotólise do formaldeído

A fotólise do formaldeído pode ocorrer por duas $\operatorname{rotas}^{1,3,38,39}$ :

$\mathbf{H C H O}+$ hv $(290-310 \mathrm{~nm}) \rightarrow \mathrm{H}^{\bullet}+\mathrm{HCO}^{\bullet}$
$\mathbf{H C H O}+\mathrm{h} v(320-350 \mathrm{~nm}) \rightarrow \mathrm{H}_{2}+\mathrm{CO}$

Os radicais formados na reação 22 reagem com oxigênio para formar radicais hidroperoxi $\left(\mathrm{HO}_{2}{ }^{\circ}\right)$ e monóxido de carbono $(\mathrm{CO})$ :

$\mathrm{H}^{\cdot}+\mathrm{O}_{2} \rightarrow \mathrm{HO}_{2} \cdot$

$\mathrm{HCO}^{\circ}+\mathrm{O}_{2} \rightarrow \mathrm{HO}_{2}^{\cdot}+\mathrm{CO}$

Esse mecanismo é a principal via de consumo de formaldeído em áreas não poluídas. O tempo de vida desta espécie com relação à fotólise é de aproximadamente $6,3 \mathrm{~h}$ no verão e $8,1 \mathrm{~h}$ no inverno em um dia claro ${ }^{1,3}$. Entretanto, em áreas poluídas, a reação com radicais HO` se constitui em outra importante via de remoção de formaldeído da atmosfera. Esses mecanismos juntos podem ser considerados a maior fonte de radicais $\mathrm{HO}_{2} \cdot$ na atmosfera ${ }^{1,37} \mathrm{e}$, consequentemente, uma importante fonte de $\mathrm{H}_{2} \mathrm{O}_{2}$.

\section{Outros compostos carbonílicos}

Os compostos carbonílicos fotolisam quando expostos à radiação, na região do ultravioleta próximo, com produção de radicais peroxialquila ou peroxi-arila, radicais $\mathrm{HO}_{2}{ }^{\circ}$, monóxido de carbono e, no caso de cetonas, aldeídos. A fotólise ocorre segundo quatro rotas já identificadas, como pode ser representado pelas reações abaixo:

aldeídos:

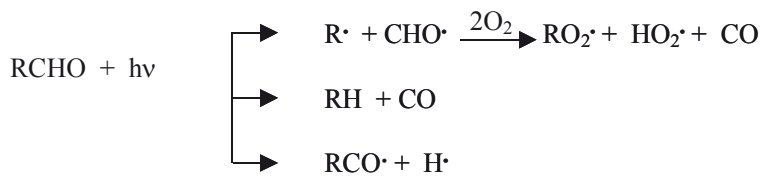

cetonas:

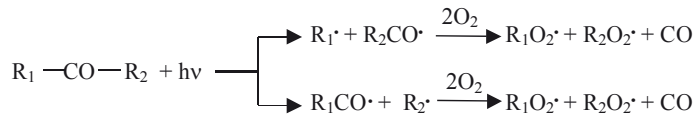

$\mathrm{R}_{1}-\mathrm{CO}-\mathrm{CH}_{2}-\mathrm{CH}_{2}-\mathrm{CH}_{2}-\mathrm{R}_{2}+\mathrm{hv} \longrightarrow \mathrm{R}_{1} \mathrm{CO} \cdot+\mathrm{CH}_{3} \cdot+\mathrm{CH}_{2}=\mathrm{CH}-\mathrm{R}_{2}$

$\mathrm{R}_{1}-\mathrm{CO}-\mathrm{CH}_{2}-\mathrm{CH}_{2}-\mathrm{R}_{2}+\mathrm{hv} \longrightarrow \mathrm{R}_{1} \mathrm{CHO}+\mathrm{CH}_{2}=\mathrm{CH}-\mathrm{R}_{2}$

Por exemplo, a fotólise do acetaldeído pode ocorrer por três rotas:

$\mathrm{CH}_{3} \mathrm{CHO}+\mathrm{h} v \longrightarrow \mathrm{CH}_{3}^{-}+\mathrm{HCO}^{\circ}$
$\mathrm{CH}_{3} \mathrm{CHO}+\mathrm{h} v \longrightarrow \mathrm{CH}_{3} \mathrm{CO}+\mathrm{H}^{\circ}$
$\mathrm{CH}_{3} \mathrm{CHO}+\mathrm{h} \mathrm{C} \longrightarrow \mathrm{CH}_{4}+\mathrm{CO}$

O tempo de vida do acetaldeído com relação a fotólise é de aproximadamente 3,3 dias no verão e 5 dias no inverno ${ }^{1,3,17}$. Estudos ${ }^{40,41}$ do efeito do comprimento de onda na fotólise indicaram que a rota mostrada na reação 30a é a mais favorável na faixa de comprimento de onda estudada, de 290 a 331 nm, com produção máxima em 300 nm.

Desta forma, os compostos carbonílicos aumentam os níveis atmosféricos de monóxido de carbono (CO) e podem ser considerados os principais precursores de radicais livres na atmosfera, entre os quais radicais hidroperóxido $\left(\mathrm{HO}_{2}{ }^{*}\right)$ e, conseqüentemente, uma importante fonte de $\mathrm{H}_{2} \mathrm{O}_{2}$. Os radicais livres gerados iniciam uma série de processos de oxidação de $\mathrm{NO}$ a $\mathrm{NO}_{2}$, influenciando a formação do ozônio, característico do "smog" fotoquímico.

\section{Reação com radicais $\mathrm{HO}^{*}$}

Reações do formaldeído com radicais $\mathrm{HO}^{*}$ e $\mathrm{HO}_{2}{ }^{*}$

A reação de formaldeído com radicais $\mathrm{HO}^{\bullet}$ ocorre por perda de um átomo de hidrogênio ${ }^{1,3,12}$ :

$\mathrm{HCHO}+\mathrm{HO}^{*} \rightarrow \mathrm{H}_{2} \mathrm{O}+\mathrm{HCO}^{*}$

Os radicais $\mathrm{HCO}^{\bullet}$ formados reagem com $\mathrm{O}_{2}$ (reação 25) para gerar $\mathrm{HO}_{2}{ }^{\circ}$ e $\mathrm{CO}$, enquanto os radicais $\mathrm{HO}_{2}{ }^{\circ}$ podem reagir com formaldeído por adição:

$\mathrm{HCHO}+\mathrm{HO}_{2}^{\cdot} \rightarrow\left(\mathrm{HO}_{2} \mathrm{CH}_{2} \mathrm{O}^{*}\right) \rightleftarrows \mathrm{O}_{2} \cdot \mathrm{CH}_{2} \mathrm{OH}$ 
A reação acima é reversível e os radicais $\mathrm{O}_{2}{ }^{\circ} \mathrm{CH}_{2} \mathrm{OH}$ podem tornar a formar formaldeído, sofrer dissociação ou reação com $\mathrm{HO}_{2}$, segundo as reações 33 e 34 :

$2 \mathrm{O}_{2}{ }^{\circ} \mathrm{CH}_{2} \mathrm{OH} \rightarrow 2 \mathrm{O}^{\circ} \mathrm{CH}_{2} \mathrm{OH}+\mathrm{O}_{2}$

$\mathrm{O}_{2} \cdot{ }^{2} \mathrm{CH}_{2} \mathrm{OH}+\mathrm{HO}_{2} \cdot \rightarrow \mathrm{HO}_{2}{ }^{\circ} \mathrm{CH}_{2} \mathrm{OH}+\mathrm{O}_{2}$

Os radicais formados nas reações 33 e 34, produzem ácido fórmico:

$\mathrm{O}^{\circ} \mathrm{CH}_{2} \mathrm{OH}+\mathrm{O}_{2} \rightarrow \mathrm{HCOOH}+\mathrm{HO}_{2} \cdot$

$\mathrm{HO}_{2} \cdot \mathrm{CH}_{2} \mathrm{OH} \rightarrow \mathrm{HCOOH}+\mathrm{H}_{2} \mathrm{O}$

Estas reações podem gerar uma quantidade significativa de ácido fórmico em atmosferas muito poluídas, contribuindo para a chuva ácida, pois este ácido apresenta uma constante de ionização relativamente alta ${ }^{42}$, da ordem de $1,80 \times 10^{-4}$

\section{Outros compostos carbonílicos}

Com exceção do formaldeído, os compostos carbonílicos sofrem fotooxidação com produção dos nitratos de peroxialquila (PANs) ou nitratos de peroxiarila ${ }^{1,3,12}$. Os nitratos de peroxialquila e os nitratos de peroxiarila são compostos extremamente fitotóxicos e irritantes para os olhos, cujo mecanismo de formação, a partir de aldeídos, pode ser representado pelas reações 37 a 39:

$$
\begin{aligned}
& \mathrm{RCHO}+\mathrm{HO}^{*} \rightarrow \mathrm{RCO}^{*}+\mathrm{H}_{2} \mathrm{O} \\
& \mathrm{RCO}^{*}+\mathrm{O}_{2} \rightarrow \mathrm{RCOO}_{2}^{*} \\
& \mathrm{RCOO}_{2}^{\cdot}+\mathrm{NO}_{2} \rightarrow \mathrm{RCOO}_{2} \mathrm{NO}_{2}
\end{aligned}
$$

Em áreas urbanas poluídas, a fotooxidação dos aldeídos é a principal rota de formação dos PANs, principalmente em locais distante de fontes de NO, pois os radicais alquilperóxido formados na reação 38 podem oxidar $\mathrm{NO}$ a $\mathrm{NO}_{2}$ (reação 40 ):

$\mathrm{RCOO}_{2}^{\cdot}+\mathrm{NO} \rightarrow \mathrm{RCO}_{2}^{\cdot}+\mathrm{NO}_{2}$

\section{Reação com radicais $\mathrm{NO}_{3}{ }^{\cdot}$}

À noite, na ausência de irradiação solar e, conseqüentemente, na ausência de espécies como $\mathrm{HO}^{*}$ e $\mathrm{HO}_{2}^{*}$, a reação dos compostos carbonílicos com radicais $\mathrm{NO}_{3}{ }^{\circ}$, gerados a partir da reação de $\mathrm{NO}_{2}$ com ozônio (reação 41), torna-se uma importante rota de remoção destes compostos da atmosfera ${ }^{1,3,43}$, resultando na produção de PANs (reações 42, 38 e 39):

$\mathrm{NO}_{2}+\mathrm{O}_{3} \rightarrow \mathrm{NO}_{3}^{\cdot}+\mathrm{O}_{2}$

$\mathbf{R C H O}+\mathrm{NO}_{3} \cdot \rightarrow \mathrm{RCO}^{*}+\mathrm{HONO}_{2}$

$\mathrm{RCO}^{\circ}+\mathrm{O}_{2} \rightarrow \mathrm{RCOO}_{2}$

$\mathrm{RCOO}_{2}^{\cdot}+\mathrm{NO}_{2} \rightarrow \mathbf{R C O O}_{2} \mathrm{NO}_{2}$

Estudos recentes ${ }^{29}$ sugerem que a reação $\mathrm{NO}_{3}{ }^{\cdot}$ - aldeídos pode gerar concentrações significativas de radicais livres $\left(\mathrm{HO}_{2}{ }^{\circ}, \mathrm{CH}_{3} \mathrm{COO}_{2}{ }^{\circ}\right.$, entre outros) e produtos reativos de grande importância, como por exemplo $\mathrm{HONO}_{2}, \mathrm{H}_{2} \mathrm{O}_{2}$ e $\mathrm{CH}_{3} \mathrm{COO}_{2} \mathrm{NO}_{2}(\mathrm{PAN})$.

\section{Processos heterogêneos}

Os processos heterogêneos de remoção dos compostos carbonílicos da atmosfera abrangem a deposição seca e a deposição úmida ${ }^{1,3,44,45}$, as quais são pouco estudados.

A deposição seca compreende o processo de transporte de poluentes, na fase gasosa ou na forma de pequenas partículas, para o nível do solo, e posterior absorção e/ou adsorção em superfícies (solo, vegetação, lagos, oceanos e rios, entre outras) sem antes terem sido dissolvidos em gotas de água ${ }^{46}$. Por outro lado, a deposição úmida compreende o processo de dissolução de poluentes em nuvens, fumaça, chuva, neve e neblina, e posterior precipitação dessas na superfície da terra, oceanos e outras superfícies aquosas ${ }^{46}$.

A deposição úmida é um processo de remoção de grande importância para os CC, pois esses compostos estão entre os poluentes atmosféricos mais solúveis em água, em especial o formaldeído apresenta uma alta solubilidade (180 $\mathrm{cm}^{3}$ gás. $\mathrm{cm}^{-3}$ água). Além destes aspectos, os aldeídos, nas suas formas hidratadas, apresentam baixa sensibilidade à fotodecomposição devido à formação de gem-diois e à limitada insolação, o que torna a neblina e as nuvens um ambiente ideal para o acúmulo destes compostos ${ }^{1,3}$.

Em meio aquoso o formaldeído reage formando o gem-diol (reação 43). $\mathrm{O}$ ataque de radicais $\mathrm{OH}^{*}$ ao gem-diol pode produzir ácido fórmico ${ }^{47,48}$, segundo as reações 44 e 45 :

$\mathrm{HCHO}+\mathrm{H}_{2} \mathrm{O} \rightleftarrows \mathrm{HOCH}_{2} \mathrm{OH}$

$\mathrm{CH}_{2}(\mathrm{OH})_{2}+\mathrm{HO}^{\cdot} \rightarrow \mathrm{CH}^{\cdot}(\mathrm{OH})_{2}+\mathrm{H}_{2} \mathrm{O}$

$\mathrm{CH}^{\circ}(\mathrm{OH})_{2}+\mathrm{O}_{2} \rightarrow \mathrm{HCOOH}+\mathrm{HO}_{2}^{*}$

$\mathrm{O}$ ácido fórmico pode ser removido ${ }^{1}$ por volatilização ou por oxidação com radicais $\mathrm{HO}^{*}$ para produzir $\mathrm{CO}_{2}$ e um segundo radical $\mathrm{HO}_{2} \cdot$

$\mathrm{HCOOH} \rightleftarrows \mathrm{H}^{+}+\mathrm{HCOO}^{-}$

$\mathrm{HCOO}^{-}+\mathrm{HO}^{*} \rightarrow \mathrm{HO}^{-}+\mathrm{HCOO}^{*}$

$\mathrm{HCOO}^{\circ}+\mathrm{O}_{2} \rightarrow \mathrm{CO}_{2}+\mathrm{HO}_{2}$

A fotooxidação de compostos carbonílicos, em especial de aldeídos, em aerossóis e gotas de chuva é a maior fonte de radicais $\mathrm{HO}_{2}{ }^{\circ}$ e, conseqüentemente $\mathrm{H}_{2} \mathrm{O}_{2}$. O peróxido de hidrogênio $\left(\mathrm{H}_{2} \mathrm{O}_{2}\right)$ é um oxidante muito forte, o qual oxida dióxido de enxofre $\left(\mathrm{SO}_{2}\right)$ a sulfato, segundo as reações 49 e 50 :

$\mathrm{SO}_{2}+\mathrm{H}_{2} \mathrm{O} \rightleftarrows \mathrm{H}^{+}+\mathrm{HSO}_{3}^{-}$

$\mathrm{HSO}_{3}^{-} \stackrel{\mathrm{H}_{2} \mathrm{O}_{2}}{\rightleftarrows} \mathrm{H}^{+}+\mathrm{SO}_{4}^{2-}$

No entanto, o formaldeído pode inibir a oxidação de S(IV) a $\mathrm{S}(\mathrm{VI})$ através de dois mecanismos principais mostrados a seguir ${ }^{49-55}$ : a) Formação de um aduto formaldeído-bissulfito (ácido hidroximetanosulfônico - $\left.\mathrm{OHCH}_{2} \mathrm{SO}_{3}^{-}: \mathrm{HMSA}\right)^{45-53}$ :

$\mathrm{HCHO}_{(\mathrm{aq})}+\mathrm{HSO}_{3}^{-} \rightleftarrows \mathrm{OHCH}_{2} \mathrm{SO}_{3}^{-}$

ou

$\mathrm{CH}_{2}(\mathrm{OH})_{2}+\mathrm{HSO}_{3}^{-} \rightleftarrows \mathrm{OHCH}_{2} \mathrm{SO}_{3}^{-}+\mathrm{H}_{2} \mathrm{O}$

A primeira dissociação do HMSA é forte, entretanto a segunda é parcial, sendo o $\mathrm{pK}_{2}$ igual a $10,2^{47}$.

$\begin{array}{ll}\mathrm{HO}_{3} \mathrm{SCH}_{2} \mathrm{OH} \rightleftarrows \mathrm{HO}_{3} \mathrm{SCH}_{2} \mathrm{O}^{-}+\mathrm{H}^{+} & \mathrm{pK}_{1} \\ \mathrm{HO}_{3} \mathrm{SCH}_{2} \mathrm{O}^{-} \rightleftarrows \mathrm{O}_{3} \mathrm{SCH}_{2} \mathrm{O}^{-}+\mathrm{H}^{+} & \mathrm{pK}_{2}\end{array}$

Os cálculos de equilíbrio indicam que a formação de HMSA pode contribuir com uma unidade de $\mathrm{pH}$ na acidez da gota de chuva ou neblina, quando a concentração de formaldeído excede $10 \mathrm{ppbv}^{54}$.

A eficiência de formaldeído como reserva de S(IV) pode ser atribuída a quatro fatores ${ }^{54}$ : (a) o formaldeído apresenta uma alta solubilidade em água, atribuída à sua hidratação para formar metileno glicol 
$\left(\mathrm{CH}_{2}(\mathrm{OH})_{2}\right)$; (b) o HMSA tem uma constante de formação termodinamicamente favorável, $\left[\mathrm{k}=6,6 \times 10^{9}\left(\mathrm{~mol}_{\mathrm{L}} \mathrm{L}^{-1}\right)^{-1}\right]$; (c) a rápida cinética de formação do HMSA, em meio levemente ácido, permite que a reação ocorra em tempo menor que o tempo de vida de nuvens e neblinas; e, finalmente, (d) o formaldeído é um poluente abundante em áreas urbanas poluídas (cerca de 30 - 75\% dos aldeídos totais ${ }^{1}$ ).

Olson e Hoffmann ${ }^{54}$ mostraram que a constante cinética de adição de $\mathrm{HSO}_{3}^{-} \mathrm{e} \mathrm{SO}_{3}^{-}$ao grupo carbonílico aumenta com a adição de grupos $\alpha$-substituintes a este grupo, tornando-o mais eletrofílico. Este estudo verificou que os adutos de S(IV) formados com hidroxiacetaldeído, glioxal e ácido glioxálico, altamente solúveis em água, são potencialmente maiores reservas de S(IV) que o formaldeído, para iguais concentrações destes compostos. Entretanto, a importância de cada um destes compostos, como reserva de $\mathrm{S}(\mathrm{IV})$, depende de sua concentração relativa na atmosfera, onde é sabido, o formaldeído é consideravelmente mais abundante.

De Andrade e Tanner ${ }^{49}$ e, de Oliveira e de Andrade ${ }^{50}$ mostraram que a reação de acetaldeído com o íon bissulfito não é eficiente. Para as condições utilizadas na reação ${ }^{49}$, apenas $8,4 \%$ do acetaldeído foi convertido a ácido hidroxietanosulfônico (HESA), enquanto que, para formaldeído a conversão em ácido hidroximetanosulfônico (HMSA) foi total.

a)Reação com $\mathrm{H}_{2} \mathrm{O}_{2}$, que resulta na produção de ácido fórmico ${ }^{47,48}$ :

$2 \mathrm{HCHO}+\mathrm{H}_{2} \mathrm{O}_{2} \rightarrow 2 \mathrm{HCOOH}$

Assim como para o formaldeído, os aldeídos de massa molar mais elevada também formam gem-diois (reações 55 e 56), os quais sofrem reações semelhantes ao gem-diol do formaldeído:

$\mathrm{RCHO}_{(\mathrm{g})} \rightarrow \mathrm{RCHO}_{(\mathrm{a})}$

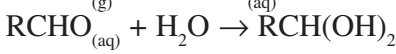

Os ácidos formados pelos processos de remoção dos CC por deposição úmida contribuem de forma significativa para a acidez da chuva e acidificação de lagos.

\section{NÍVEIS DE CONCENTRAÇÃO}

Os compostos carbonílicos estão distribuídos na atmosfera nas fases gasosa, líquida (neve, neblina, nuvem, entre outras) ou associados ao material particulado. Em todas essas formas os mais abundantes são os dois primeiros membros da série, formaldeído e acetaldeído $o^{1,3}$.

\section{Fase gasosa}

O conhecimento dos níveis de concentração atmosférica dos compostos carbonílicos é de extrema importância para diversas áreas da química ambiental e de controle da poluição, como por exemplo na modelagem de oxidantes fotoquímicos $\left(\mathrm{O}_{3}, \mathrm{PANs}, \mathrm{H}_{2} \mathrm{O}_{2}, \mathrm{NO}_{\mathrm{x}}\right)$; em experimentos de simulação em câmara de "smog"; no estudo da poluição em ambientes internos; na higiene industrial; no controle de emissões veiculares, industriais e outras; no estudo fotoquímico de hidrocarbonetos e outros compostos orgânicos ${ }^{1}$. No entanto, até a década de 80 são poucos os dados relativos aos valores de concentração de $\mathrm{CC}$ no ar, principalmente em áreas remotas, devido às limitações dos métodos analíticos quanto à sensibilidade e seletividade.

Áreas não poluídas

Os dados dos níveis de concentração atmosférica de compostos carbonílicos, em áreas remotas, são poucos e, na maioria das vezes, limitam-se apenas a formaldeído e, algumas vezes, acetaldeído.

Nestas áreas o CC mais abundante é o formaldeído, cujas concentrações em áreas costeiras, montanhas e oceanos, variam de 0,040 - 12 ppbv, onde a maioria das concentrações estão entre 0,083 - 2,2 $\mathrm{ppbv}^{22}$.

As concentrações ambientais de formaldeído e acetaldeído em diversas regiões do mundo estão apresentadas na Tabela 5. Os dados de duas diferentes áreas remotas, apresentados para o Brasil, indicam faixas de concentrações semelhantes para formaldeído e acetaldeído, como também estes dados concordam com as faixas encontradas para outras regiões.

Tabela 5. Concentrações atmosféricas de formaldeído e acetaldeído em áreas não poluídas

\begin{tabular}{|c|c|c|c|c|c|}
\hline Local & Período & $\mathrm{HCHO}(\mathrm{ppbv})^{\mathrm{a}}$ & $\mathrm{CH}_{3} \mathrm{CHO}(\mathrm{ppbv})^{\mathrm{a}}$ & $\mathrm{N}^{\mathrm{b}}$ & Ref. \\
\hline Jülich - Alemanha & $05-10 / 78$ & $0,1-6,5(2,14)$ & & 72 & 62 \\
\hline Eifel - Alemanha & $24 / 10 / 78$ & $0,58-1,3(1,07)$ & & 04 & 62 \\
\hline Oceano Pacífico & $10-13 / 05 / 75$ & $0,8-2,0(1,3)$ & & 10 & 63 \\
\hline Oceanos Pacífico e Índico & $01-04 / 76$ & $<0,8-11(3,4)$ & & 53 & 63 \\
\hline Jülich - Alemanha & 01 e $02 / 80$ & $0,08-0,43(0,27)$ & & 30 & 21 \\
\hline Costa Oeste da Irlanda & $04 / 80$ & $0,09-0,52(0,23)$ & & 37 & 21 \\
\hline Oceano Atlântico & 10 e $11 / 80$ & $0,10-0,63$ & & 151 & 21 \\
\hline Whiteface Mountain, Wilmington, NY & $14-20 / 08 / 83$ & $0,6-2,6$ & $0,2-0,8$ & 21 & 64 \\
\hline Ontário - Canadá & 07 e $08 / 1988$ & $(1,8)$ & $(0,6)$ & & 65 \\
\hline Biscayne Bay, Miami, FL & $10 / 88$ & $(1,7)$ & $(1,8)$ & & 66 \\
\hline Caribean Sea $\left(15^{\circ} \mathrm{N}, 66^{\circ} \mathrm{W}\right)$ & $10 / 88$ & $(0,54)$ & $(0,4)$ & 30 & 66 \\
\hline Cacha-Pregos, Ilha de Itaparica, BA, Brasil & $25-27 / 02 / 89$ & $0,2-2,5(1,2)$ & $0,4-2,3(1,2)$ & 20 & 16 \\
\hline Lagoa Verde, Mutuipe, BA, Brasil & $14-17 / 11 / 91$ & $0,16-4,65(1,46)$ & $0,49-5,90(2,13)$ & 17 & 16 \\
\hline Wank - Alemanha & 10/1991 & $(1,3)$ & $(0,6)$ & & 67 \\
\hline Schauinsland - Alemanha & 09/1992 & $0,4-2,3(1,0)$ & $0,1-1,8(0,7)$ & 22,35 & 67 \\
\hline \multirow[t]{2}{*}{ Floresta Amazônica - Brasil } & Fevereiro 99 & $0,5-3,1$ & $0,4-1,9$ & & 68 \\
\hline & Outubro 99 & $0,8-13$ & $<0,4-6,3$ & & 68 \\
\hline Ontário - Canadá & & $10-17$ & & & 69 \\
\hline
\end{tabular}

a ( ) Valor médio, ${ }^{\mathrm{b}}$ Número de medidas, ${ }^{\mathrm{c}}$ Referência 
Áreas poluídas

\section{Ambientes externos}

O maior interesse nos níveis de concentração de poluentes em áreas urbanas deve-se principalmente à maior concentração de fontes emissoras e à alta densidade demográfica nestes locais. Nestes locais há uma grande variação na concentração atmosférica de compostos carbonílicos, resultante da complexidade dos processos de introdução, formação in situ e remoção destes compostos.
A maioria dos dados de concentração atmosférica de CC em áreas urbanas no exterior é em locais nos Estados Unidos da América ${ }^{56-60}$ onde a identificação e quantificação destes compostos, principalmente aldeídos, tanto na atmosfera como em gases de exaustão, vem sendo bastante estudadas nas últimas três décadas. A maioria destes dados limita-se às concentrações de formaldeído e acetaldeído, sendo que alguns valores para diferentes localidades no exterior estão apresentados na Tabela 6, enquanto dados para outros CC de maior massa molar estão apresentados na Tabela 7.

Tabela 6. Concentrações atmosféricas de formaldeído e acetaldeído em áreas urbanas no exterior

\begin{tabular}{|c|c|c|c|c|c|c|}
\hline Local & Período & $\mathrm{HCHO}(\mathrm{ppbv})^{\mathrm{a}}$ & $\mathrm{CH}_{3} \mathrm{CHO}(\mathrm{ppbv})^{\mathrm{a}}$ & $\begin{array}{c}{[\mathrm{HCHO}] /} \\
{\left[\mathrm{CH}_{3} \mathrm{CHO}\right]^{\mathrm{a}}}\end{array}$ & $\mathrm{N}^{\mathrm{b}}$ & Ref. \\
\hline Osaka - Japão & 05 e $07 / 78$ & $21,0-34,3(27,5)$ & $1,8-8,0(4,8)$ & 7,2 & 06 & 70 \\
\hline $\begin{array}{l}\text { University of California - Los Angeles } \\
\text { Campus }\end{array}$ & 05 e $06 / 80$ & $2-40(20,2)$ & $0-32(9,5)$ & 2,85 & 38 & 2 \\
\hline Havery Mudd College, Claremont, CA & 09 e $10 / 80$ & $3,0-48,1(24,3)$ & $2,9-34,8(14,4)$ & 2,25 & 02 & 2 \\
\hline Los Angeles, CA & $07-10 / 80$ & $18,5-60,2(43,7)$ & $13,5-37,6(22,1)$ & 2,08 & 06 & 36 \\
\hline Burbank, CA & & $(67,8)$ & $(12,2)$ & 6,23 & 02 & 36 \\
\hline Pasadena, CA & & 52,5 & 12,7 & 4,13 & 01 & 36 \\
\hline Pacoima, CA & & 4,6 & 2,9 & 1,59 & 01 & 36 \\
\hline Newhall, CA & & 33,1 & 7,6 & 4,36 & 01 & 36 \\
\hline Rosemead, CA & & $(42,8)$ & $(28,6)$ & 1,77 & 02 & 36 \\
\hline Covina, CA & & 27,4 & 56,4 & 0,49 & 01 & 36 \\
\hline Cucamunga, CA & & 42,0 & 38,3 & 1,10 & 01 & 36 \\
\hline El Monte, CA & & $(63,5)$ & $(30,1)$ & 2,15 & 03 & 36 \\
\hline San Dimas, CA & & 33,6 & 14,8 & 2,27 & 01 & 36 \\
\hline Upland, CA & & 33,6 & 19,0 & 1,78 & 01 & 36 \\
\hline Azusa, CA & & $0,7-35,4(15,5)$ & $0,5-9,9(4,6)$ & 4,69 & 18 & 36 \\
\hline Lenox, CA & & $0,5-39,6(8,9)$ & $0,1-2,7(1,1)$ & 32,25 & 18 & 36 \\
\hline Osaka - Japão & 1982 & $1,6-8,5(4,9)$ & $1,7-9,0(4,4)$ & 1,14 & 06 & 72 \\
\hline Long Island, NY & $07 / 82-05 / 83$ & $0,9-48(7,5)$ & $>0,5-3,5(2,9)$ & $2,59^{\mathrm{d}}$ & 138 & 56 \\
\hline Centro de Los Angeles, CA & $9-11 / 81$ & $4-86$ & $2-39$ & 1,45 & & 5 \\
\hline Pittisburg, PA & 15 e 16/04/81 & $(18,5 \pm 6,7)$ & $(1,4 \pm 0,8)$ & $13,2^{\mathrm{d}}$ & 12 & 71 \\
\hline Chicago, IL & 27 e $28 / 04 / 81$ & $(11,3 \pm 3,8)$ & $(2,1 \pm 0,9)$ & $5,4^{\mathrm{d}}$ & & 71 \\
\hline Downey, CA & $28 / 2-01 / 3 / 84$ & $(15,5 \pm 11,9)$ & $(8,5 \pm 6,3)$ & $1,8^{\mathrm{d}}$ & & 71 \\
\hline Houston, TX & 18 e 19/03/84 & $(3,8 \pm 8,3)$ & $(2,2 \pm 1,7)$ & $1,7^{\mathrm{d}}$ & & 71 \\
\hline Denver, CO & 1 e $2 / 04 / 84$ & $(2,3 \pm 1,8)$ & $(1,0 \pm 0,5)$ & $2,3^{\mathrm{d}}$ & & 71 \\
\hline Pamona College Campus, Claremont, CA & $11-19 / 09 / 85$ & $1,5-11,2(5,1)$ & $1,0-9,0(4,1)$ & 1,42 & 21 & 57 \\
\hline Anaheim, CA & $09 / 88-09 / 89$ & $(5,3)$ & $(3,5)$ & $1,5^{\mathrm{d}}$ & 57 & 58 \\
\hline Azusa, CA & & $(5,0)$ & $(3,1)$ & $1,6^{\mathrm{d}}$ & 57 & 58 \\
\hline Burbank, CA & & $(6,0)$ & $(4,8)$ & $1,2^{\mathrm{d}}$ & 57 & 58 \\
\hline Hawtorne, CA & & $(6,0)$ & $(2,9)$ & $2,1^{\mathrm{d}}$ & 57 & 58 \\
\hline Upland, CA & & $(5,3)$ & $(3,9)$ & $1,4^{\mathrm{d}}$ & 57 & 58 \\
\hline Los Angeles, CA & & $(6,1)$ & $(3,8)$ & $1,6^{\mathrm{d}}$ & 57 & 58 \\
\hline Palm Spring, Los Angeles, CA & $06 / 89-07 / 90$ & $(1,8)$ & $(5,0)$ & 0,4 & 62 & 59 \\
\hline Perris, Los Angeles, CA & $06 / 89-07 / 90$ & $(2,8)$ & $(10,3)$ & 0,3 & 62 & 59 \\
\hline Tucson, AZ & $12 / 89-02 / 90$ & $(1,8)$ & $(3,8)$ & 0,5 & 23 & 59 \\
\hline Lost Mountain, Atlanta & 07 e $08 / 93$ & $0,8-6,0(2,7)$ & $0,6-5,6(2,6)$ & $0,3-1,9(1,06)$ & 52 & 60 \\
\hline Georgia Institute of Technology (6 m) & & $1,0-5,1(2,9)$ & $0,7-2,8(3,1)$ & $0,5-2,8(1,08)$ & 55 & 60 \\
\hline Georgia Institute of Technology (30 m) & & $0,6-7,3(2,9)$ & $0,6-7,7(3,1)$ & $0,5-2,8(1,02)$ & 55 & 60 \\
\hline South De Kaalb, Atlanta & & $0,4-8,3(3,0)$ & $0,6-8,4(3,2)$ & $0,2-3,3(1,01)$ & 55 & 60 \\
\hline Atlanta (total) & & $0,4-8,3(3,0)$ & $0,6-8,4(3,0)$ & $0,2-3,3(1,04)$ & 217 & 60 \\
\hline \multirow[t]{3}{*}{ Albuquerque, Novo México } & verão 93 & 13,9 & 6,6 & & 129 & 73 \\
\hline & inverno 1994 & 16,8 & 7,3 & & 136 & 73 \\
\hline & inverno 1995 & 3,2 & 1,4 & & 53 & 73 \\
\hline \multirow[t]{3}{*}{ Socorro, Novo México } & verão 93 & 7,6 & 4,1 & & 37 & 73 \\
\hline & inverno 1994 & 1,3 & 1,3 & & 25 & 73 \\
\hline & inverno 1995 & 14,2 & 5,4 & & 51 & 73 \\
\hline Langmuir, Novo México & inverno 1995 & 10,1 & 2,7 & & 21 & 73 \\
\hline
\end{tabular}

${ }^{\mathrm{a}}$ ( ) Valor médio, ${ }^{\mathrm{b}}$ Número de medidas, ${ }^{\mathrm{c}}$ Referência, ${ }^{\mathrm{d}}$ Razão em função da média das concentrações 
Tabela 7. Concentrações atmosféricas para CC de massa molar maior que 44 g.mol ${ }^{-1}(\mathrm{C}>2)$

\begin{tabular}{|c|c|c|c|c|}
\hline Local & Período & $\mathrm{CC}$ & Conc. $(p p b v)^{\mathrm{a}}$ & Ref. $^{b}$ \\
\hline Claremont, CA & 09-10/1980 & $\begin{array}{l}\text { propionaldeído } \\
\text { n-butiraldeído } \\
\text { 2-butanona } \\
\text { benzaldeído }\end{array}$ & $\begin{array}{c}<\mathrm{LD}-14(6,8) \\
<\mathrm{LD}-7,0(1,8) \\
<\mathrm{LD}-14,0(4,5) \\
<\mathrm{LD}-1,0(0,5)\end{array}$ & 2 \\
\hline Osaka - Japão & $1982 / 1983$ & propionaldeído & $0,8-5,9$ & 72 \\
\hline Claremont, CA & $11-19 / 09 / 85$ & $\begin{array}{l}\text { propionaldeído } \\
\text { n-butiraldeído } \\
\text { n-pentanaldeído } \\
\text { benzaldeído }\end{array}$ & $\begin{array}{c}0,2-1,4 \\
0,2-0,8 \\
<0,1-0,6 \\
<0,1-0,8\end{array}$ & 57 \\
\hline São Paulo - Brasil & $10 / 86$ e 06 e $07 / 88$ & $\begin{array}{l}\text { acroleína } \\
\text { propanona } \\
\text { propionaldeído } \\
\text { benzaldeído } \\
\text { glioxal } \\
\text { metil glioxal }\end{array}$ & $\begin{array}{l}0,1-1,1 \\
0,2-3,1 \\
0,2-1,0 \\
0,2-4,4 \\
0,2-1,3 \\
0,2-1,8\end{array}$ & 13 \\
\hline Rio de Janeiro - Brasil & 08 e 09/87 & $\begin{array}{l}\text { propanona } \\
\text { propionaldeído }\end{array}$ & $\begin{array}{l}<0,5-3,8 \\
<0,1-3,0\end{array}$ & 13 \\
\hline Albuquerque, Novo México & inverno 94 & $\begin{array}{l}\text { propionaldeído } \\
\text { propanona } \\
\text { metil etil cetona } \\
\text { metacroleína } \\
\text { propionaldeído } \\
\text { propanona } \\
\text { metil etil cetona } \\
\text { metacroleína } \\
\text { propionaldeído }\end{array}$ & $\begin{array}{c}(0,7) \\
(4,3) \\
(<0,7) \\
(<0,7) \\
(<0,5) \\
(0,3) \\
(0,9) \\
(<0,7) \\
(1,8)\end{array}$ & 73 \\
\hline Socorro, Novo México & inverno 95 & $\begin{array}{l}\text { propionaldeído } \\
\text { propanona } \\
\text { metil etil cetona } \\
\text { metacroleína } \\
\text { propionaldeído } \\
\text { propanona } \\
\text { metil etil cetona } \\
\text { metacroleína } \\
\text { propionaldeído } \\
\text { propanona } \\
\text { metil etil cetona } \\
\text { metacroleína }\end{array}$ & $\begin{array}{c}(1,0) \\
(7,6) \\
(<0,7) \\
(<0,7) \\
(0,7) \\
(1,2) \\
(3,2) \\
(<0,7) \\
(<0,5) \\
(7,1) \\
(1,4) \\
(0,8)\end{array}$ & 73 \\
\hline Langmuir, Novo México & Inverno 95 & $\begin{array}{l}\text { propionaldeído } \\
\text { propanona } \\
\text { metil etil cetona } \\
\text { metacroleína }\end{array}$ & $\begin{array}{l}(<0,5) \\
(11,4) \\
(1,1) \\
(1,7)\end{array}$ & 73 \\
\hline
\end{tabular}

a ( ) valor médio, ${ }^{\text {b Referência }}$

Não existem dados de concentrações atmosféricas de CC no Brasil, antes da introdução de etanol hidratado como combustível automotivo, o que dificulta tentativas no sentido de estudar o impacto ambiental deste combustível. Porém, alguns dados disponíveis são mostrados na Tabela 8.

A comparação entre as concentrações atmosféricas de formaldeído e acetaldeído em áreas não urbanas (Tabela 5) e em áreas urbanas (Tabelas 6 e 8), revela que estas concentrações são maiores em áreas urbanas, devido ao maior número de fontes de emissão direta desses compostos e de seus precursores.

As concentrações atmosféricas para áreas urbanas no exterior (Tabela 6) mostram variações nos valores para concentrações médias de formaldeído e acetaldeído, respectivamente, de 1,8 - 67,8 e 1,0 - 56,4 ppbv. Para o Brasil ${ }^{16,61}$ (Tabela 8) essa variação é de 1,8 - 26,4 e 3,5 - 37,1 ppbv para formaldeído e acetaldeído, respectivamente; sem considerar os dados de ambientes fechados como túneis, estacionamentos, entre outros. Esses valores indicam faixas de concentrações maiores para o exterior em relação ao Brasil.

Um outro aspecto que deve ser considerado é que as razões $[\mathrm{HCHO}] /\left[\mathrm{CH}_{3} \mathrm{CHO}\right]$, no exterior são sempre maiores que 1, enquanto que para o Brasil, na maioria dos dados apresentados, são menores que 1. Esse fato mostra um perfil distinto do Brasil em relação a outros países onde o etanol não é utilizado como combustível automotivo, indicando que a utilização deste pode afetar grandemente o perfil dos níveis de concentração atmosférica de $\mathrm{CC}^{12,16}$.

\section{Ambientes internos}

Em ambientes internos as taxas de troca de ar são baixas levando a um aumento considerável na concentração de poluentes químicos e biológicos ${ }^{77}$ e, como consequiência, a uma baixa qualidade do ar. Além 
Tabela 8. Concentrações atmosféricas de formaldeído e acetaldeído em áreas urbanas no Brasil

\begin{tabular}{|c|c|c|c|c|c|c|}
\hline Local & Período & $\mathrm{HCHO}(\mathrm{ppbv})^{\mathrm{a}}$ & $\mathrm{CH}_{3} \mathrm{CHO}(\mathrm{ppbv})^{\mathrm{a}}$ & $\begin{array}{l}\mathrm{HCHO} / \\
\mathrm{CH}_{3} \mathrm{CHO}^{\mathrm{a}}\end{array}$ & $\mathrm{N}^{\mathrm{b}}$ & Ref. \\
\hline Vila Isabel - RJ & $07 / 85$ & $20-30(26,4)$ & $23-55(37,1)$ & $0,50-0,92(0,73)$ & 15 & 12 \\
\hline PUC, Gávea - RJ & $07 / 85$ & $1,2-2,4(1,8)$ & $1,9-5,4$ & $0,30-0,77(0,52)$ & 10 & 12 \\
\hline Túnel Sta. Barbara - RJ & $04 / 85$ & $4,3-17,6(10,6)$ & $8,0-29,1(17,1)$ & $0,60 \pm 0,02$ & 8 & 12 \\
\hline Praça do Correio - SP & $23 / 10 / 86$ & $3,7-8,0(5,4)$ & $11,2-19,2(16,1)$ & $0,23-0,44(0,33)$ & 3 & 13 \\
\hline USP - SP & 06 e $07 / 88$ & $2,3-13,3(8,8)$ & $0,9-15,2(7,6)$ & $0,50-7,39(2,47)$ & 8 & 13 \\
\hline CETESB - SP & $07 / 88$ & $8,5-19,3(13,5)$ & $2,3-15,9(8,0)$ & $1,07-3,70(2,21)$ & 4 & 13 \\
\hline Túnel Sta. Barbara - RJ & $01 / 87$ & (65) & $(236)$ & $0,28^{\mathrm{d}}$ & 2 & 13 \\
\hline R. Cosme Velho - RJ & $09 / 87$ & $0,7-6,5(4,1)$ & $2,6-6,6(4,7)$ & $0,17-1,31(0,90)$ & 10 & 13 \\
\hline Vitória, Salvador - BA & $09 / 88$ & $6-13(8,9)$ & $15-21(19)$ & $0,26-0,62(0,47)$ & 3 & 13 \\
\hline CETESB, Congonhas - SP & 1988 & $7,5-26,2(16,3)$ & $6,5-55,5(30,6)$ & $0,38-0,96(0,58)$ & 47 & 74 \\
\hline $\mathrm{USP}-\mathrm{SP}$ & $25-28 / 07 / 89$ & $0,7-10,6(4,5)$ & $1,9-29,7(10,5)$ & $0,23-0,76(0,45)$ & 32 & 74 \\
\hline Túnel Rebouças - RJ & $08 / 01 / 87$ & 154 & 307 & 0,50 & 1 & 74 \\
\hline Estação da Lapa, Salvador - BA & 29 e $30 / 01 / 92$ & $31,7-76,1(52,1)$ & $8,8-16,2(11,9)$ & $3,29-6,00(4,41)$ & 11 & 16 \\
\hline $\begin{array}{l}\text { Estacionamento Fechado de } \\
\text { um Shopping, Salvador-BA }\end{array}$ & $4 / 04 / 92$ & $7,35-10,02(8,25)$ & $10,87-14,34(12,56)$ & $0,60-0,76(0,66)$ & 5 & 16 \\
\hline $\begin{array}{l}\text { Estacionamento Fechado do } \\
\text { Centro Empresarial Iguatemi, }\end{array}$ & $11 / 11 / 92$ & $\begin{array}{l}29,52-74,92 \\
(44,29)\end{array}$ & $48,68-91,39(68,66)$ & $0,44-0,85(0,65)$ & 7 & 16 \\
\hline Salvador - BA & $26 / 02 / 92$ & & $54,61-93,32(71,77)$ & $0,81-1,35(1,15)$ & 4 & 16 \\
\hline $\begin{array}{l}\text { Túnel Américo Simas, Salvador } \\
\text { - BA }\end{array}$ & $27-31 / 10 / 91$ & $\begin{array}{l}76,61-88,37 \\
(79,52)\end{array}$ & $0,64-6,86(3,51)$ & $0,45-2,42(1,01)$ & 18 & 16 \\
\hline $\begin{array}{l}\text { Pq. Cruz Aguiar, Rio Vermelho, } \\
\text { Salvador - BA }\end{array}$ & $20-24 / 12 / 91$ & $1,33-4,11(2,92)$ & $3,0-14,6(6,3)$ & $1,1-2,7(1,8)$ & 24 & 16 \\
\hline $\begin{array}{l}\text { Baixa dos Sapateiros, } \\
\text { Salvador - BA }\end{array}$ & & $4,3-16,3(10,5)$ & & & & \\
\hline Rio de Janeiro, Brasil & $12 / 95$ & $9,8-79,8(32)$ & $5,7-16,8(11,6)$ & & 11 & 75 \\
\hline Água Funda - SP & $2-14 / 08 / 99$ & $1,0-46,7$ & $1,4-50,9$ & & & 76 \\
\hline Cidade Universitária - SP & $2-14 / 08 / 99$ & $2,6-45,6$ & $1,2-56,6$ & & & \\
\hline $\begin{array}{l}\text { Instituto de Química - } \\
\text { Araraquara -SP - UNESP }\end{array}$ & & $23,0-91,8^{\mathrm{e}}$ & & & 8 & 77 \\
\hline
\end{tabular}

a ( ) Valor médio, ${ }^{\mathrm{b}}$ Número de medidas, ${ }^{\mathrm{c}}$ Referência, ${ }^{\mathrm{d}}$ Razão em função da média das concentrações, ${ }^{\mathrm{e}}$ aldeído total como formaldeído

deste aspecto, deve-se considerar que a população passa a maior parte do dia em recintos fechados como, por exemplo, casas, escritórios, lojas, ambientes de lazer (cinemas, parques fechados, teatros, etc.). Desta forma, a exposição nestes ambientes torna-se mais crítica devido ao maior tempo de exposição e às elevadas concentrações de poluentes.

A baixa qualidade do ar de interiores tem sido relacionada a um número de efeitos adversos à saúde humana, levando a Organização Mundial da Saúde (OMS) a classificar a Síndrome do Edifício Doente (SED) como um problema de saúde pública. A Síndrome do Edifício Doente está relacionada a situações onde mais de $20 \%$ dos ocupantes de um determinado edifício experimentam efeitos adversos à saúde e ao conforto, e esses efeitos desaparecem ao abandonar o edifício, sem que outras causas para o problema sejam detectadas. Entre as reclamações mais comuns estão irritação dos olhos; irritação e obstrução nasal; desidratação e irritação da pele; irritação e secura na garganta; dor de cabeça; letargia e cansaço generalizado, levando à perda de concentração ${ }^{78,79}$. Assim, a Síndrome do Edifício Doente implica, necessariamente, em um local de trabalho desagradável, com eficiência de trabalho reduzida e aumento nas faltas.

O problema da qualidade de ar em ambientes fechados (QAI) agravou-se a partir da década de 70, com o movimento mundial de conservação de energia. Mudanças arquitetônicas no ambiente interno, com o intuito de economizar energia através da melhor eficiência nos aparelhos de refrigeração e aquecimento, levou à construção de prédios de escritórios e residenciais com vedação térmica mais eficiente, surgindo os chamados prédios selados. Simultaneamente, houve um significativo aumento na diversidade de produtos para forração, acabamento e mobiliário, os quais podem emitir espécies químicas passíveis de serem dispersas no ar de interiores ${ }^{78}$. Entre estas espécies químicas merecem destaque os compostos orgânicos voláteis (COVs) presentes na composição de materiais de construção, limpeza e mobiliário.

Entre os COVs, o formaldeído e outros aldeídos têm sido associados à Síndrome do Edifício Doente; além disso, estes compostos apresentam potencial mutagênico. Em ambientes internos existe um grande número de fontes destes compostos que compreendem móveis e decoração, materiais de limpeza, materiais de construção, fumo, processos de combustão, incursão de ar externo, entre outros. Desta forma, desde a década de 80 , os pesquisadores têm se empenhado em determinar as concentrações de compostos carbonílicos em ambientes internos. Essas concentrações têm sido medidas principalmente em residências e escritórios . A Tabela 9 apresenta concentrações de compostos carbonílicos em ambientes internos em diversas cidades, inclusive brasileiras.

Os níveis de concentração de aldeídos em ambientes internos são, na maioria das vezes, maiores quando comparados com ambientes externos ${ }^{1,69,75}$. Por exemplo, os resultados obtidos por Brickus e colaboradores ${ }^{75}$, para um edifício de escritório no Rio de Janeiro, apresentaram uma razão média de concentração interna/externa de 2,6 para formaldeído e, 1,3 para acetaldeído. 
Tabela 9. Concentrações de aldeídos em ambientes internos

\begin{tabular}{|c|c|c|c|}
\hline Local & Composto Carbonílico & Concentração (ppbv) $)^{\mathrm{a}}$ & Ref. $^{\mathrm{b}}$ \\
\hline Residências móveis (trailers) em Pittsburg (EUA) & aldeídos totais & $100-800(360)$ & 1 \\
\hline Residências em Pittsburg (EUA) & aldeídos totais & $500^{\mathrm{c}}(150)$ & 1 \\
\hline Residências móveis (trailers) em Washington (EUA) & formaldeído & $(100-440)$ & 1 \\
\hline Residências móveis (trailers) em Minnesota (EUA) & formaldeído & $(400)$ & 1 \\
\hline Residências móveis (trailers) em Wisconsin (EUA) & formaldeído & $20-4200$ & 1 \\
\hline Prédios públicos nos EUA & formaldeído & $(880) 210^{c}$ & 1 \\
\hline \multirow[t]{7}{*}{ Catedral de Salvador, Bahia } & formaldeído & $10-34(23,3)$ & 13 \\
\hline & acetaldeído & $9,2-35(22,1)$ & \\
\hline & propanona & $(11,9)$ & \\
\hline & propionaldeído & $(0,5)$ & \\
\hline & benzaldeído & $(1,0)$ & \\
\hline & glioxal & $0,6^{\mathrm{d}}$ & \\
\hline & metil glioxal & $0,3^{\mathrm{d}}$ & \\
\hline \multirow[t]{7}{*}{ Museu Costa Pinto, Salvador - Bahia } & formaldeído & $2,3-22(11,2)$ & 13 \\
\hline & acetaldeído & $21-34(31,7)$ & \\
\hline & propanona & $(9,5)$ & \\
\hline & propionaldeído & $(0,5)$ & \\
\hline & benzaldeído & $(3,6)$ & \\
\hline & glioxal & $(0,6)$ & \\
\hline & metil glioxal & $(0,55)$ & \\
\hline \multirow[t]{7}{*}{ Coleção de Arte Privada, Salvador - Bahia } & formaldeído & $(20)$ & 13 \\
\hline & acetaldeído & $(17,5)$ & \\
\hline & propanona & $(11,2)$ & \\
\hline & propionaldeído & $(0,6)$ & \\
\hline & benzaldeído & $0,5^{\mathrm{d}}$ & \\
\hline & glioxal & $0,17^{\mathrm{d}}$ & \\
\hline & metil glioxal & $(0,25)$ & \\
\hline $\begin{array}{l}\text { Vários ambientes fechados em Ontário - Canadá } \\
\text { (casas, apartamentos, escolas, escritórios, etc.) }\end{array}$ & formaldeído & $10-380$ & 69 \\
\hline Laboratório de Analítica - UNESP, Araraquara - SP & formaldeído & $84,0^{\mathrm{e}}$ & 77 \\
\hline Entrada do Instituto de Química - UNESP, Araraquara - SP & formaldeído & $50,0^{\mathrm{e}}$ & 77 \\
\hline Biblioteca do Instituto de Química - UNESP, Araraquara - SP & formaldeído & $23,0^{\mathrm{e}}$ & 77 \\
\hline \multirow[t]{2}{*}{ Edifício de escritórios, Rio de Janeiro, Brasil } & formaldeído & $9,8-79,8(32)$ & 75 \\
\hline & acetaldeído & $1,3-20(11,4)$ & \\
\hline \multirow[t]{7}{*}{ Ambientes internos de trabalho, São Paulo, Brasil } & formaldeído & $188^{c}(29)$ & 80 \\
\hline & acetaldeído & $68^{\mathrm{c}}(17)$ & \\
\hline & propanona & $85^{\mathrm{c}}(25)$ & \\
\hline & propanal & $5,2^{\mathrm{c}}(1,5)$ & \\
\hline & butenal & $2,0^{\mathrm{c}}(0,2)$ & \\
\hline & $\mathrm{C}_{4}$ isômeros ${ }^{\mathrm{f}}$ & $3,2^{\mathrm{c}}(1,4)$ & \\
\hline & glutaraldeído & $121^{\mathrm{c}}(79)$ & \\
\hline Residências na Alemanha (1984 - 1986) & formaldeído & $(33,4-35)$ & 81 \\
\hline 252 Residências na Alemanha (1986 - 1993) & formaldeído & $361^{\mathrm{c}}(66,2)$ & 81 \\
\hline Residências móveis (trailers) na Alemanha & formaldeído & $389,2^{\mathrm{c}}$ & 81 \\
\hline Residências no Norte da Europa & formaldeído & $(22,2-33,4)$ & 81 \\
\hline Novos escritórios (trailers) nos EUA & formaldeído & $(102,3-139)$ & 81 \\
\hline Edifícios públicos nos EUA (museus, teatros, etc.) & formaldeído & $11,1-68,3$ & 82 \\
\hline
\end{tabular}

a ( ) valor médio, ${ }^{\mathrm{b}}$ Referência, ${ }^{\mathrm{c}}$ maior valor, ${ }^{\mathrm{d}} \mathrm{N}=1$, ${ }^{\mathrm{e}}$ aldeído total como formaldeído, ${ }^{\mathrm{f}} \mathrm{n}$-butanal + 2-butanona + metacroleína

\section{Material particulado (aerossol)}

Os compostos carbonílicos são compostos polares bastante solúveis em água podendo interagir com partículas de material condensado, adsorver em fuligem ou solubilizar em chuva, névoa, nuvem, entre outros. Desta forma, a deposição seca e a deposição úmida devem ser consideradas como importantes processos de remoção destes compostos da atmosfera. Apesar disso, a maioria dos estudos envolvendo estes compostos na atmosfera estão voltados para fase gasosa e poucos dados estão disponíveis na literatura com relação às concentrações desses compostos em aerossol ou na fase aquosa.

Assim como na fase gasosa, o formaldeído e acetaldeído são os compostos carbonílicos mais abundantes no aerossol atmosférico. Concentrações de compostos carbonílicos em aerossol estão apresentadas na Tabela 10.

Os resultados obtidos por Klippel e Warneck ${ }^{83}$, Grosjean $^{2}$ e de Andrade et $a l .{ }^{45}$ indicam que a razão entre as concentrações de formaldeído e acetaldeído na fase particulada/fase vapor, é sempre menor que $10^{-2}$. Isto indica que mais de $99 \%$ da massa total destes aldeídos encontra-se na fase gasosa, e menos que $1 \%$ encontra-se 
Tabela 10. Concentrações de compostos carbonílicos em material particulado

\begin{tabular}{llll}
\hline Local & Composto carbonílico & Concentração $\left(\mathrm{ng} / \mathrm{m}^{3}\right)^{\mathrm{a}}$ & Ref. $^{\mathrm{b}}$ \\
\hline Salvador, Bahia & formaldeído & $7-27,8$ \\
& acetaldeído & $3-89$ & 45 \\
Claremont, Califórnia & formaldeído & $2-264$ \\
& acetaldeído & $2-406$ \\
& propionaldeído & $4-268$ \\
& butiraldeído & $7-98$ \\
Deuselbach - Alemanha & 2-butanona & $13-110$ \\
Ireland - Alemanha & formaldeído & $12,3-117(40)$ \\
Mainz - Alemanha & & $(4,9-8,2)$ \\
Deuselbach - Alemanha & & 63 \\
Ireland - Alemanha & formaldeído & 40,9 \\
\hline
\end{tabular}

a ( ) valor médio, ${ }^{\mathrm{b}}$ Referência

associada ao aerossol. Entretanto, mesmo as baixas concentrações encontradas no aerossol ${ }^{2,45,83}$ revelaram-se muito maiores que aquelas previstas por um simples equilíbrio entre as fases aquosa (do aerossol) e gasosa.

Segundo Klippel e Warneck ${ }^{83}$ e Grosjean ${ }^{2}$, a concentração do $\mathrm{CC}$ no aerossol pode ser estimada a partir da equação abaixo:

$\mathrm{C}_{1}=\mathrm{HC}_{\mathrm{g}} \mathrm{W}$

onde $\mathrm{C}_{1}$ e $\mathrm{C}_{\mathrm{g}}$ representam, respectivamente, as concentrações dos $\mathrm{CC}$ no aerossol e na fase gasosa; W é a concentração de água no aerossol e H é a constante da Lei de Henry para o CC. As constantes da Lei de Henry para formaldeído e acetaldeído são, respectivamente, 7,51 x $10^{-8} \mathrm{~m}^{3} / \mu \mathrm{g}$ e $2,11 \times 10^{-7} \mathrm{~m}^{3} / \mu \mathrm{g}$, a $25^{\circ} \mathrm{C}^{45}$. As concentrações de formaldeído e acetaldeído medidas por Klippel e Warneck ${ }^{83}$, Grosjean ${ }^{2}$ e, de Andrade et $a l .{ }^{45}$ foram cerca de 1000 vezes maiores que as preditas para o equilíbrio (equação 57). Este fato pode ser explicado por alguns fatores ${ }^{2}$ : (a) o aerosssol não pode ser descrito adequadamente pelo modelo aplicado às soluções diluídas; (b) a presença de um filme orgânico modifica consideravelmente a interface fase líquida-fase gasosa (por exemplo, coeficiente de transferência de massa); (c) o equilíbrio é deslocado para a fase aerossol a partir das reações dos $\mathrm{CC}$ para formar adutos (por exemplo, com $\mathrm{SO}_{2}$ e $\mathrm{NH}_{3}$ ); (d) ocorrência de artefato de amostragem, como por exemplo, a adsorção de $\mathrm{CC}$ gasosos na camada de material particulado depositada no filtro de amostragem.

De modo contrário à fase gasosa, Grosjean ${ }^{2}$ e de Andrade et al ${ }^{45}$ encontraram concentrações de acetaldeído, medidas em todas as amostras de aerossol, maiores que as concentrações para formaldeído. Isto foi explicado pelo fato do formaldeído formar adutos ou produtos de condensação mais estáveis que aqueles formados pelo acetaldeído ${ }^{50} \mathrm{e}$, como consequiência, a reação de derivatização do primeiro não é eficiente para as condições usadas na análise.

\section{Fase aquosa}

Os CC são moléculas polares bastante solúveis em água, onde existem essencialmente nas suas formas hidratadas, e por isso podem ser facilmente removidos da atmosfera por hidrometeoros, ou seja, qualquer produto da condensação ou da sublimação de vapor d'água atmosférica, como chuva, neve, nevoeiro, neblina, geada, entre outros. Desta forma, estes compostos podem apresentar concentrações significativas em águas de chuva, gelo, neve e névoa.

Assim como na fase gasosa e no aerossol, o formaldeído e acetaldeído são os CC mais abundantes na fase aquosa. Concentra- ções de CC em água de nuvem, chuva e neblina estão apresentadas na Tabela 11.

A análise das concentrações de compostos carbonílicos em fase aquosa atmosférica, especialmente de formaldeído, levam às seguintes conclusões:

a) a concentração de CC em nuvem, neblina, chuva, entre outras, é maior em áreas urbanas que em áreas não urbanas ${ }^{85,86}$;

b) a concentração de formaldeído total é consideravelmente maior que a concentração de $\mathrm{HMSA}^{87}$. Rao e Collett $\mathrm{Jr}^{87}$ determinaram relações [formaldeído total] / [HMSA] variando de 4 a 90 e o formaldeído livre variou de 75 a $99 \%$ da concentração total deste composto;

c) a análise de formaldeído em 116 amostras de água de chuva em Wilmington, Carolina do Norte, no período de junho de 1996 a fevereiro de $1998^{85}$, indicou que este composto compreende cerca de 3\% do carbono orgânico dissolvido;

d) a água de chuva é uma importante fonte de formaldeído para águas superficiais (oceanos, rios e lagos), já que em águas de chuvas a concentração deste composto é aproximadamente 3 vezes a concentração em águas superficiais ${ }^{85}$;

e) a concentração de formaldeído em águas de chuvas é maior no verão que em outros períodos do ano ${ }^{85,88}$;

f) não foi encontrada correlação entre a concentração de formaldeído e o volume de precipitação ${ }^{85}$, o que sugere um fornecimento contínuo deste composto durante a precipitação. Evidências indicam que parte deste fornecimento é devido à produção fotoquímica na fase aquosa.

g) existe relação entre as concentrações de $\mathrm{HCHO}, \mathrm{H}_{2} \mathrm{O}_{2}$ e $\mathrm{S}(\mathrm{VI})$ na fase aquosa atmosférica ${ }^{85}$

h) Kieber e colaboradores ${ }^{85}$ calcularam uma velocidade de deposição úmida, pela chuva, para formaldeído de 4,6 mmol.m ${ }^{-2}$.ano ${ }^{-1}$;

i) as concentrações de formaldeído aumentam com a diminuição do tamanho da $\operatorname{gota}^{87}$;

j) a concentração de aldeídos em chuva é extremamente dependente do volume de precipitação. Os resultados indicam que, quanto maior o volume de precipitação, menor a concentração de aldeídos ${ }^{88}$.

\section{EFEITOS PARA A SAÚDE HUMANA E OUTROS ECOSSISTEMAS}

Os compostos carbonílicos (CC) são comumente absorvidos pelo homem a partir da inalação de seus vapores, absorção cutânea e ingestão. De modo geral esses compostos são irritantes para os olhos, pele e trato respiratório; além do que, alguns compostos apresentam 
Tabela 11. Concentrações de compostos carbonílicos em fase aquosa

\begin{tabular}{|c|c|c|c|c|c|c|c|c|c|c|c|}
\hline \multirow[t]{2}{*}{ Local } & \multirow[t]{2}{*}{ Amostra } & \multirow[b]{2}{*}{$\mathrm{C}_{1}{ }^{\mathrm{a}}$} & \multirow[b]{2}{*}{$\mathrm{C}_{2}{ }^{\mathrm{b}}$} & \multicolumn{4}{|c|}{ Concentração $\left(m g . L^{-1}\right)$} & \multirow[b]{2}{*}{$\mathrm{MEC}^{\mathrm{g}}$} & \multirow[b]{2}{*}{$\mathrm{PE}^{\mathrm{h}}$} & \multicolumn{2}{|c|}{$\operatorname{Ref}^{\mathrm{j}}$} \\
\hline & & & & $\mathrm{C}_{3}{ }^{\mathrm{c}}$ & $\mathrm{GX}^{\mathrm{d}}$ & $\mathrm{MGX}^{\mathrm{e}}$ & $\mathrm{BU}^{\mathrm{f}}$ & & & $B Z^{\mathrm{i}}$ & \\
\hline Oeste da Alemanha & $\begin{array}{l}\text { Água de } \\
\text { chuva }\end{array}$ & $0,012-0,106$ & - & - & - & - & - & - & - & - & \\
\hline Mainz - Alemanha & $\begin{array}{l}\text { Água de } \\
\text { chuva }\end{array}$ & $(0,17)$ & - & - & - & - & - & - & - & - & 83 \\
\hline $\begin{array}{l}\text { Áreas urbanas na } \\
\text { Irlanda e Oeste da } \\
\text { Alemanha }\end{array}$ & $\begin{array}{l}\text { Água de } \\
\text { chuva }\end{array}$ & $(0,140)$ & - & - & - & - & - & - & - & - & 84 \\
\hline $\begin{array}{l}\text { Atol Enewetak, } \\
\text { Irlanda }\end{array}$ & $\begin{array}{l}\text { Água de } \\
\text { chuva }\end{array}$ & 0,08 & - & - & - & - & - & - & - & - & 84 \\
\hline $\begin{array}{l}\text { Wilmington, Carolina } \\
\text { do Norte }\end{array}$ & Chuva & $>0,0003-0,39$ & - & - & - & - & - & - & - & - & 85 \\
\hline Fairbanks, AK & $\begin{array}{l}\text { Neblina de } \\
\text { gelo }\end{array}$ & $0,50-1,16$ & $0,007-0,13$ & $0-0,21$ & - & - & - & - & - & $0,08-0,32$ & 286 \\
\hline Henninger Flats, CA & Nuvem & $\begin{array}{c}0,01-1,08 \\
(0,45)\end{array}$ & $\begin{array}{c}0-0,59 \\
(0,10)\end{array}$ & $\begin{array}{c}0-0,86 \\
(0,13)\end{array}$ & - & - & $\begin{array}{c}0-0,052 \\
(0,07)\end{array}$ & $\begin{array}{c}20-0,47 \\
\quad(0,04)\end{array}$ & $\begin{array}{c}0-2,56 \\
(0,23)\end{array}$ & $\begin{array}{c}0-0,57 \\
(0,05)\end{array}$ & 86 \\
\hline Long Beach, CA & Neblina & 0,25 & 0,11 & 0,73 & - & - & - & - & 0,14 & - & 86 \\
\hline Marina del Ray, CA & Neblina & 0,56 & 0,10 & 0,58 & - & - & - & - & 0,15 & - & 86 \\
\hline Marina del Ray, CA & Nevoeiro & 2,30 & 0,15 & 0,63 & - & - & - & - & 0,12 & - & 86 \\
\hline Pasadena, CA & Nevoeiro & $0,20-0,34$ & $0,08-0,17$ & $0,68-0,84$ & - & - & $0-0,052$ & - & $0,12-0,15$ & - & 86 \\
\hline Morro Bay, CA & Nevoeiro & $0,03-019$ & $0-0,06$ & - & - & - & - & - & - & - & 86 \\
\hline San Nicholas Island, CA & Nevoeiro & - & $0,06-0,09$ & - & - & - & - & - & - & - & 86 \\
\hline La Jolla Peak, CA & $\begin{array}{l}\text { Água de } \\
\text { nuvem }\end{array}$ & $0,26-0,90$ & - & - & - & - & - & - & - & - & 87 \\
\hline Angora Peak, OR & $\begin{array}{l}\text { Água de } \\
\text { nuvem }\end{array}$ & $0,13-0,66$ & - & - & - & - & - & - & - & - & 87 \\
\hline Mt. Mitchell, NC & $\begin{array}{l}\text { Água de } \\
\text { nuvem }\end{array}$ & $0,40-1,09$ & - & - & - & - & - & - & - & - & 87 \\
\hline Whiteface Mountain, NY & $\begin{array}{l}\text { Água de } \\
\text { nuvem }\end{array}$ & $0,15-0,42$ & - & - & - & - & - & - & - & - & 87 \\
\hline Bakersfield, CA & $\begin{array}{l}\text { Água de } \\
\text { nuvem }\end{array}$ & $2,5-5,5$ & - & - & - & - & - & - & - & - & 87 \\
\hline Los Angeles, CA & $\begin{array}{l}\text { Água de } \\
\text { chuva }\end{array}$ & $\begin{array}{c}0,045-1,9 \\
(0,099)\end{array}$ & $\begin{array}{c}0,0044-0,10 \\
(0,0090)\end{array}$ & - & $\begin{array}{c}0,0058- \\
0,36(0,012)\end{array}$ & $\begin{array}{r}0,0072- \\
0,50(0,01\end{array}$ & 4) - & - & - & - & 88 \\
\hline Los Angeles, CA & $\begin{array}{l}\text { Água de } \\
\text { nuvem }\end{array}$ & $0,3-4,2$ & - & - & - & - & - & - & - & - & 89 \\
\hline Pasadena, CA & $\begin{array}{l}\text { Água de } \\
\text { nevoeiro }\end{array}$ & $3,1-3,5$ & - & - & - & - & - & - & - & - & 90 \\
\hline Lenox, CA & $\begin{array}{l}\text { Água de } \\
\text { nevoeiro }\end{array}$ & $4,6-12,8$ & - & - & - & - & - & - & - & - & 90 \\
\hline Oildale, CA & $\begin{array}{l}\text { Água de } \\
\text { nevoeiro }\end{array}$ & $6,1-14,4$ & - & - & - & - & - & - & - & - & 90 \\
\hline Upland, CA & $\begin{array}{l}\text { Água de } \\
\text { nevoeiro }\end{array}$ & $6,1-8,6$ & - & - & - & - & - & - & - & - & 90 \\
\hline Corvallis, Oregon & Neblina & $0,4-3,0(1,8)$ & - & - & - & - & - & - & - & - & 91 \\
\hline Corvallis, Oregon & $\begin{array}{l}\text { Água de } \\
\text { chuva }\end{array}$ & $0,008-0,1$ & - & - & - & - & - & - & - & -92 & 9394 \\
\hline Riverside, CA & Neblina & - & - & - & $1,5-7,4$ & $2,3-20$ & - & - & - & - & 95 \\
\hline Los Angeles, CA & $\begin{array}{l}\text { Água de } \\
\text { nuvem }\end{array}$ & $0,24-1,9$ & - & - & $0,12-1,8$ & $0,14-1$, & - & - & - & - & 96 \\
\hline
\end{tabular}

${ }^{\mathrm{a}} \mathrm{C}_{1}=$ formaldeído, ${ }^{\mathrm{b}} \mathrm{C}_{2}=$ acetaldeído, ${ }^{\mathrm{c}} \mathrm{C}_{3}=$ propanona + acroleína + propionaldeído, ${ }^{\mathrm{d}} \mathrm{GX}=$ Glioxal, ${ }^{\mathrm{e}} \mathrm{MGX}=$ metilglioxal,

${ }^{\mathrm{f}} \mathrm{BU}=$ butiraldeído, ${ }^{\mathrm{g}} \mathrm{MEC}=$ metil etil cetona, ${ }^{\mathrm{h}} \mathrm{PE}=$ pentanaldeído, ${ }^{\mathrm{i}} \mathrm{BZ}=$ Benzaldeído, ${ }^{\mathrm{j}}$ Ref. $=$ Referência, ()$=$ valor médio. 
características fitotóxicas, teratogênicas, mutagênicas e carcinogênicas ${ }^{1,97,98}$. Essas propriedades são mais acentuadas nos CC de menor massa molar, com insaturação e substituintes halogenados ${ }^{1,97}$.

$\mathrm{O}$ interesse no estudo das concentrações desses compostos em ambientes e em alimentos (água ${ }^{99}$, bebidas alcoólicas ${ }^{50,99-102}$, bebidas não alcoólicas ${ }^{101}$, peixes e mariscos ${ }^{103-105}$, entre outros) tem aumentado devido aos efeitos dos CC à saúde humana e aos diversos ecossistemas.

É importante ressaltar que além dos efeitos tóxicos produzidos pelos CC à saúde humana, animais, vegetação e outros sistemas, ainda se somam aqueles resultantes dos produtos de suas reações na atmosfera, como por exemplo: ozônio, éter bis-clorometila (BCME), nitratos de peroxiacila e nitratos de peroxibenzila ${ }^{1}$.

\section{Formaldeído (HCHO)}

O formaldeído apresenta odor irritante que é percebido geralmente em cerca de $1 \mathrm{ppm}$. O contato direto das soluções de formaldeído com a pele pode provocar irritações, dermatites alérgicas e urticária, enquanto o contato com os olhos pode provocar sérios danos, como edema nas pálpebras e membrana conjuntiva, opacificação da córnea e perda da visão ${ }^{1}$.

O formaldeído provoca irritação em toda extensão do trato respiratório, a depender da concentração e da sensibilidade da pessoa exposta. A irritação do nariz e garganta ocorre frequientemente em concentrações entre 1 - 11 ppm. Concentrações acima de 50 ppm provocam sérios danos, tais como pneumonia, bronquite, edema pulmonar, algumas vezes resultando em morte quando a concentração excede 100 ppm $^{1,22}$.

Estudos comprovaram que o formaldeído é um agente mutagênico e cancerígeno, cuja exposição prolongada de homens e ratos a este composto pode provocar câncer nasal e nasofaringeal ${ }^{1,22,106}$. Existem evidências do efeito teratogênico de formaldeído em seres huma$\operatorname{nos}^{1}$. Seus efeitos citotóxico e genotóxico têm sido atribuídos ao ataque nucleofílico a grupos aminas e sulfidrilas presentes em muitas biomoléculas ${ }^{97,107}$.

A reação do formaldeído e ácido clorídrico em ar úmido (equação 58), gera o éter bis-clorometila (BCME), o qual é altamente cancerígeno no homem, afetando principalmente as vias respiratórias ${ }^{1}$.

$$
2 \mathrm{HCl}+2 \mathrm{HCHO} \rightleftarrows \mathrm{ClCH}_{2} \mathrm{OCH}_{2} \mathrm{Cl}+\mathrm{H}_{2} \mathrm{O}
$$

Os limites máximos de exposição ao formaldeído recomendados por órgãos internacionais são de 1 ppm (NIOSH) para uma jornada de trabalho diária de $8 \mathrm{~h} ; 0,1 \mathrm{ppm}$ para ambientes externos (American Industrial Hygiene Association) e 0,2 ppm para ambientes internos (American Society of Heating, Refrigerating and Air-Conditioning Engineers $)^{1,22}$.

\section{Acetaldeído $\left(\mathrm{CH}_{3} \mathrm{CHO}\right)$}

O acetaldeído é menos irritante e tóxico que o formaldeído. Em altas concentrações pode causar necrose, bronquite, albuminuria do tecido gorduroso do fígado, edema pulmonar e morte ${ }^{1,97,98}$.

Alguns estudos atribuem em parte, os efeitos da fumaça de cigarro nos pulmões ao seu elevado teor em acetaldeído $(0,98-1,31$ $\mathrm{mg}$ /cigarro), considerado um importante constituinte citotóxico e ciliostático da fumaça do tabaco ${ }^{1,98}$. Um outro efeito atribuído ao acetaldeído é o mal estar provocado pelo excesso de bebidas alcóolicas. A maior fonte de acetaldeído no organismo humano é o metabolismo do etanol.

$\mathrm{O}$ acetaldeído tem se mostrado um potente embriotóxico e teratogênico em ratos. Além disso, é um agente mutagênico e cancerígeno, podendo causar tumores nasal e laringeal ${ }^{1,98}$.

\section{Acroleína}

A acroleína é extremamente tóxica por todas as rotas de administração. Seus vapores causam severas irritações respiratórias e oculares. O contato com acroleína líquida pode produzir necrose, mesmo as soluções $1 \%$ causam sérios danos. Esse composto não tem mostrado características de agente cancerígeno ou embriotóxico, entretanto, apresenta-se como potente agente mutagênico. Seu poder de irritação dos olhos varia entre 2,5 a 5 vezes maior que a do formaldeído, a depender da concentração. A principal via de ataque da acroleína são as mucosas do trato respiratório superior. A exposição a altas concentrações pode causar edema pulmonar, ou até mesmo morte ${ }^{1}$.

Estudos mostram a alta toxicidade da acroleína para as plantas (fitotóxica) e organismos aquáticos. A "Environmental Protection Agency" (EPA) determinou que a acroleína tem efeitos tóxicos agudos e crônicos em organismos aquáticos, em concentrações tão baixas quanto 0,068 e $0,021 \mathrm{mg} / \mathrm{L}$, respectivamente; e efeitos agudos tóxicos em organismos marinhos em concentrações da ordem de $0,055 \mathrm{mg} / \mathrm{L}^{1}$.

\section{CONSIDERAÇÕES FINAIS}

A importância dos compostos carbonílicos na geração do "smog" fotoquímico já está bem estabelecida. Entretanto, muitos aspectos ainda precisam ser investigados, como por exemplo, a influência de suas fontes (queima de combustíveis, plantas, indústria) e processos de remoção na concentração atmosférica, distribuição temporal e geográfica destes compostos; influência na química atmosférica de espécies como ozônio, S(IV), óxidos de nitrogênio, nitratos de peroxiacila e nitratos de peroxiarila.

Outro fato que deve ser considerado é o pequeno número de estudos com CC de alta massa molar. A maioria dos estudos limitase a formaldeído e acetaldeído.

\section{AGRADECIMENTOS}

Os autores agradecem à CAPES, ao CNPq e ao CADCT/BA pelo suporte financeiro.

\section{REFERÊNCIAS}

1. Comittee on Aldehyde, National Research Council; Formaldehyde and Other Aldehydes, National Academy Press: Washington, DC, 1981, p. 340.

2. Grosjean, D.; Environ. Sci. Technol. 1982, 16, 254.

3. Carlier, P.; Hannachi, H.; Mouvier, G.; Atmos. Environ. 1986, 20, 2079.

4. Kalabokas, P.; Carlier, P.; Fresnet, P.; Mouvier, G.; Toupance, G; Atmos. Environ. 1988, 22, 147

5. Grosjean, D.; Fung, K.; J. Air Pollut. Control Assoc. 1984, 34, 537.

6. Altshuller, A. P.; Atmos. Environ. 1993, 27A, 21.

7. Morgan, E. D.; Tyler, R. C.; J. Chromatogr. Sci. 1977, 134, 174.

8. Stoiber, R. E.; Legett, D. C.; Jekins, T. F.; Murrmann, R. P.; Rose, J. R. W. I.; Geological Society of America Bulletin 1971, 82, 2299.

9. Miguel, A. H.; de Andrade, J. B.; J. Braz. Chem. Soc. 1990, 1, 124.

10. de Andrade, J. B.; Miguel, A. H.; Int. J. Environ. Anal. Chem. 1985, 21, 229

11. National Research Council, Toxicological and Performance Aspects of Oxygenated Motor Vehicle Fuels, National Academy Press: Washington, DC, 1996

12. Tanner, R. L.; Miguel, A. H.; de Andrade, J. B.; Gaffney, J. S.; Streit, G. E.; Environ. Sci. Technol. 1988, 22, 1026.

13. Grosjean, D.; Miguel, A. H.; Tavares, T. M.; Atmos. Environ. 1990, 24B, 101.

14. Nefussi, N.; de Assunção, J. V.; de Toledo, M. P.; Castelli; A. S.; Companhia de Saneamento Ambiental, São Paulo; Report CETESB, 1981.

15. Johnson, L.; Josefsson, B.; Marstorp, P.; Eklund, G.; Int. J. Environ. Anal. Chem. 1981, 9, 7 . 
16. de Andrade, J. B.; de Andrade, M. V.; Pinheiro, H. L. C.; J. Braz. Chem. Soc. 1998, 9, 219.

17. Pimentel, A. S.; Arbilla, G.; Quim. Nova 1997, 20, 252.

18. Pereira, P. A. P.; Santos, E. T. S.; Ferreira, T. F.; de Andrade, J. B.; Talanta 1999, 49,245.

19. Pereira, P. A. P.; de Andrade, J. B.; Quim. Nova 1998, 21, 744.

20. Akutsu, Y.; Toyoda, F.; Tomita, K. I.; Yoshizawa, F.; Tamura, M.; Yoshida, T.; Atmos. Environ. 1991, 25A, 1383.

21. Lowe, D. C.; Schmidt, U.; J. Geophys. Res. 1983, 88 , 10844.

22. United Nations Environment Programme, International Labour Organisation and World Healt Organization; Formaldehyde, Enviranmental Health Criteria 89, Geneva, 1989, p. 219.

23. Baulch, D. L.; Cox, R. A.; Hampson, R. F.; Kerr Jr., J. A.; Troe, J.; Watson, R. T.; J. Phys. Chem. 1984, 13A, 1255.

24. Atkinson, R.; Lloyd, A. C.; J. Phys. Chem. 1984, 13A, 315.

25. Grosjean, E.; de Andrade, J. B.; Grosjean, D.; Environ. Sci. Technol. 1996, $30,975$.

26. Atkinson, R.; Carter, W. P. L.; Chem. Rev. 1984, 84, 437.

27. Atkinson, R.; Atmos. Environ. 1990, 24A, 481.

28. Atkinson, R.; Tuazon, E. C.; Aschmann, S. M.; Environ. Sci. Technol. 1995, 29, 1860 .

29. Grosjean, E.; Grosjean, D.; Atmos. Environ. 1996, 30, 4107.

30. Grosjean, E.; Grosjean, D.; Environ. Sci. Technol. 1996, 30, 2036.

31. Grosjean, E.; Grosjean, D.; Environ. Sci. Technol. 1996, 30, 1321.

32. Grosjean, E.; Grosjean, D.; J. Atmos. Chem. 1996, 24, 141.

33. Grosjean, E.; Grosjean, D.; Environ. Sci. Technol. 1997, 31, 2421.

34. Grosjean, E.; Grosjean, D.; Atmos. Environ. 1998, 32, 3393.

35. Nunes, F. M. N.; Pereira, P. A. P.; de Andrade, J. B.; Quim. Nova 2000, 23, 794 .

36. Grosjean, D.; Swanson, R. D.; Ellis, C.; Sci. Total Environ. 1983, $29,65$.

37. Gunz, W. D.; Hoffman, M. R.; Atmos. Environ. 1990, 24A, 1601.

38. Horowitz, A.; Calvert, J. G.; Int, J. Chem. Kinet. 1978, 10, 713.

39. Horowitz, A.; Calvert, J. G.; Int, J. Chem. Kinet. 1978, 10, 805.

40. Horowitz, A.; Calvert, J. G.; Int, J. Chem. Kinet. 1982, 86, 3094.

41. Horowitz, A.; Calvert, J. G.; Int, J. Chem. Kinet. 1982, 86, 3105.

42. Harris, D. C.; Quantitative Chemical Analysis, W. H. Freeman and Company: New York, $4^{\text {th }}$ ed., 1995, p. 837.

43. Cantrell, C. A.; Stockwell, W. R.; Anderson, L. G.; Busarow, K. L.; Perner, D.; Schmeltekopf, A.; Calvert, J. G.; Johnston, H. S.; J. Phys. Chem. 1985, $89 A, 139$.

44. de Andrade, J. B.; Pinheiro, H. L. C.; de Andrade, M. V.; Int. J. Environ. Anal. Chem. 1993, 52, 49.

45. de Andrade, J. B.; Pinheiro, H. L. C.; de Andrade, M. V.; J. Braz. Chem. Soc. 1995, 6, 287.

46. Pitts, B. J. F.; Pitts Jr., J. N.; Atmospheric Chemistry: Fundamentals and Experimantal Techniques, John Wiley \& Sons: New York, 1986.

47. Munger, J. W.; Jacob, D. J.; Hoffman, M. R.; J. Atmos. Chem. 1984, 1, 335.

48. Adewuyi, Y. G.; Cho, S-Y.; Tsay, R-P.; Carmichael, G. R.; Atmos. Environ. 1984, 18, 2413

49. de Andrade, J. B.; Tanner, R. L.; Atmos. Environ. 1992, 26A, 819.

50. de Oliveira, A. E.; de Andrade, J. B.; Quim. Nova 1994, 17, 13.

51. Martins, C. R.; Cabral Neto, C. A.; Alves, J. J. F.; de Andrade, J. B.; J. Braz. Chem. Soc. 1999, 10, 453.

52. Boyce, S. D.; Hoffman, M. R.; J. Phys. Chem. 1984, 88A, 4740.

53. Deister, U.; Neeb, R.; Helas, G.; Warneck, P.; J. Phys. Chem. 1986, 90A, 3213

54. Olson, T. M.; Hoffman, M. R.; Atmos Environ. 1989, 23, 985.

55. Rao, X.; Collett Jr., J. L.; Environ. Sci. Technol. 1995, 29, 1023.

56. Tanner, R. L.; Zhaokun, M.; Environ. Sci. Technol. 1984, 18, 723.

57. Grosjean, D.; Atmos. Environ. 1988, 22,1637.

58. Grosjean, D.; Environ. Sci. Technol. 1991, 24, 710.

59. Grosjean, D.; Williams II, E. L.; J. Air Waste Manage. Assoc. 1992, 42, 805 .

60. Grosjean, E.; Williams II, E. L.; Grosjean, D.; J. Air Waste Manage. Assoc. 1993, 43, 469 .

61. Montero, L.; Souza, S. R.; Carvalho, L. R. F.; Pool, C.; Kazue, D.; Lorenzo, R.; Vasconcelos, P.; Pires, M. A. F.; Andrade, M. F.; Gonçalves, F. L. T.; Resumos da $23^{a}$ Reunião Anual da Sociedade Brasileira de Química, Poços de Caldas, Brasil, 2000.

62. Platt, U.; Perner, D.; Patz, H. W.; J. Geophys. Res. 1984, 84, 6329.

63. Fushimi, K.; Miyake, Y.; J. Geophys. Res. 1980, 85, 7533.
64. Shulam, P.; Newbold, R.; Hull, L. A.; Atmos. Environ. 1985, 19, 623.

65. Shepson, P. B.; Hastie, D. R.; Schiff, H. I.; Polizzi, M.; Bottenheim, J. W.; Anlauf, K.; Mackay, G. I.; Karecki, D. R.; Atmos. Environ. 1991, 25A, 2001.

66. Zhou, X.; Mopper, K.; Environ. Sci. Technol. 1990, 24, 1482.

67. Slemr, J.; Junkermann, W.; Volz-Thomas, A.; Atmos. Environ. 1996, 30, 3667.

68. de Oliva, S.; Botelho, M. L.; Perez, H. R.; Amaral, C. M.; Tavares, T. M.; Resumos da $23^{a}$ Reunião Anual da Sociedade Brasileira de Química, Poços de Caldas, Brasil, 2000.

69. Koziel, J. A.; Noah, J.; Pawliszyn, J.; Environ. Sci. Technol. 2001, 35, 1481

70. Kuwata, K.; Uebori, M.; Yamasaki, Y.; J. Chromat. Sci. 1979, 17, 264.

71. Salas, L. J.; Singh, H. B.; Atmos. Environ. 1986, 20, 1301.

72. Kuwata, K.; Uebori, M.; Yamasaki, Y.; Kuge, Y.; Anal. Chem. 1983, 55, 2013.

73. Gaffney, J. S.; Marley, N. A.; Martin, R. S.; Dixon, R. W.; Reyes, L. G.; Popp, C. J.; Environ. Sci. Technol. 1997, 31, 3053.

74. De Carvalho, C. R.; Dissertação de Mestrado, Universidade Federal de Minas Gerais, Brasil, 1992.

75. Brickus, L. S. R.; Cardoso, J. N.; de Aquino Neto, F. R.; Environ. Sci. Technol. 1998, 32, 3485.

76. Mantero, L.; Souza, S. R.; Carvalho, L. R. F.; Pool, C.; Kazue, D.; Lorenzo, R.; Vasconcellos, P. C.; Pires, M. A. F.; Andrade, M. F.; Gonçalves, F. L. T.; Resumos da $23^{a}$ Reunião Anual da Sociedade Brasileira de Qquímica, Poços de Caldas, Brasil, 2000.

77. Pereira, E. A.; Cardoso, A. A.; Dasgupta, P. K.; Quim. Nova 2001, 24, 443.

78. Brikus, L. S. R.; de Aquino Neto, F. R.; Quim. Nova 1999, 22, 65.

79. Boletim Informativo da Expo-Labor: Edição Especial da Analítica 1998, 26,5 .

80. Pires, M.; Carvalho, L. R. F.; Quim. Nova 1999, 22, 487.

81. Salthammer, T.; Indoor Air International, ULM 1994, 451

82. Grosjean, D.; Williams II, E. L.; Atmos. Environ. 1992, 26A, 2923.

83. Klippel, W.; Warneck, P.; Atmos. Environ. 1980, 14, 809.

84. Klippel, W.; Warneck, P.; Geophys. Res. Lett. 1978, 5, 177.

85. Kieber, R. J.; Rhines, M. F.; Willey, J. D.; Avery Jr., G. B.; Atmos. Environ. 1999, 33, 3659

86. Grosjean, D.; Wright, B.; Atmos. Environ. 1983, 17, 2093.

87. Rao, X.; Collett Jr., J. L.; Environ. Sci. Technol. 1995, 29, 1023.

88. Sakugawa, H.; Kaplan, I. R.; Shepard, L. S.; Atmos. Environ. 1993, 27, 203.

89. Richards, L. W.; Anderson, J. A.; Blumenthal, D. L.; McDonald, J. A.; Kok, G. L.; Lazrus, A. L.; Atmos. Environ. 1983, 17, 911.

90. Munger, J. W.; Jacob, D. J.; Waldman, J. M.; Hoffmann, M. R.; J. Geophys. Res. 1983, 88, 5109.

91. Muir, P. S.; J. Air Waste Manage. Assoc. 1991, 41, 32.

92. Zafirou, O. C.; Alford, J.; Herrera, E. T.; Peltzer, R. B.; Geophys. Res. Lett. 1980, 7, 341 .

93. Keuken, M. P.; Schoonebeek, C. A. M.; Int. J. Environ. Anal. Chem. 1989, 35, 227.

94. Thompson, A. M.; Tellus. 1980, 32, 376.

95. Munger, J. W.; Collett, J.; Daube Jr., B.; Hoffmann, M. R.; Atmos. Environ. 1989, 23, 2305.

96. Igawa, M.; Munger, J. W.; Hoffmann, M. R.; Environ. Sci. Technol. 1989, $23,556$.

97. Goldschmith, B. M.; J. Environ. Sci. Health. 1984, C2, 231.

98. Shepson, P. B.; Kleindienst, T. E.; Edney, E. O.; Nero, C. M.; Cupitt, L. T.; Caxton, L. D.; Environ. Sci. Technol. 1986, 20, 1008.

99. de Andrade, J. B.; Reis, J. O. N.; Rebouças, M. V.; Pinheiro, H. L.; de Andrade, M. V.; Quim. Anal. 1996, 15, 144.

100. de Andrade, J. B.; Bispo, M. S.; Rebouças, M. V.; Carvalho, M. L. S. M.; Pinheiro, H. L.; American Laboratory 1996, 56.

101. Tsuchiya, H.; Othani, S.; Yamada, K.; Akagiri, M.; Takagi, N.; Sato, M.; Analyst 1994, 119, 1413.

102. de Andrade, J. B.; Bravo, R. V. F.; Quim. Nova 1989, 12, 196.

103. Veloso, M. C. C.; da Silva, V. M.; Santos, G. V.; de Andrade, J. B.; J. Chromatogr. Sci. 2001, 39, 173.

104. Yasuhara, A.; Shibamoto, T.; J. Agric. Food Chem. 1995, 43, 94.

105. Radford, T.; Dalsis, D. E.; J. Agric. Food Chem. 1982, 30, 60.

106. Bernstein, R.; Stayner, L.; Elliott, L. J.; Kimbrough, R.; Falk, H.; Blair, L.; Am. Ind. Hyg. Assoc. J. 1984, 45, 778.

107. Wilson, V. L.; Foiles, P. G.; Chung, F. L.; Povey, A. C.; Frank, A. A.; Haris, C. C.; Carcinogenesis 1991, 12, 1483. 